Published in "Chemistry - A European Journal 25(44): 10262-10283, 2019"

which should be cited to refer to this work.

\title{
Advances in Porous Organic Polymers for Efficient Water Capture
}

Yearin Byun ${ }^{+}{ }^{[a]}$ Sang Hyun Je ${ }^{+}{ }^{[a]}$ Siddulu Naidu Talapaneni ${ }^{+},{ }^{[a]}$ and Ali Coskun ${ }^{*[a, b]}$

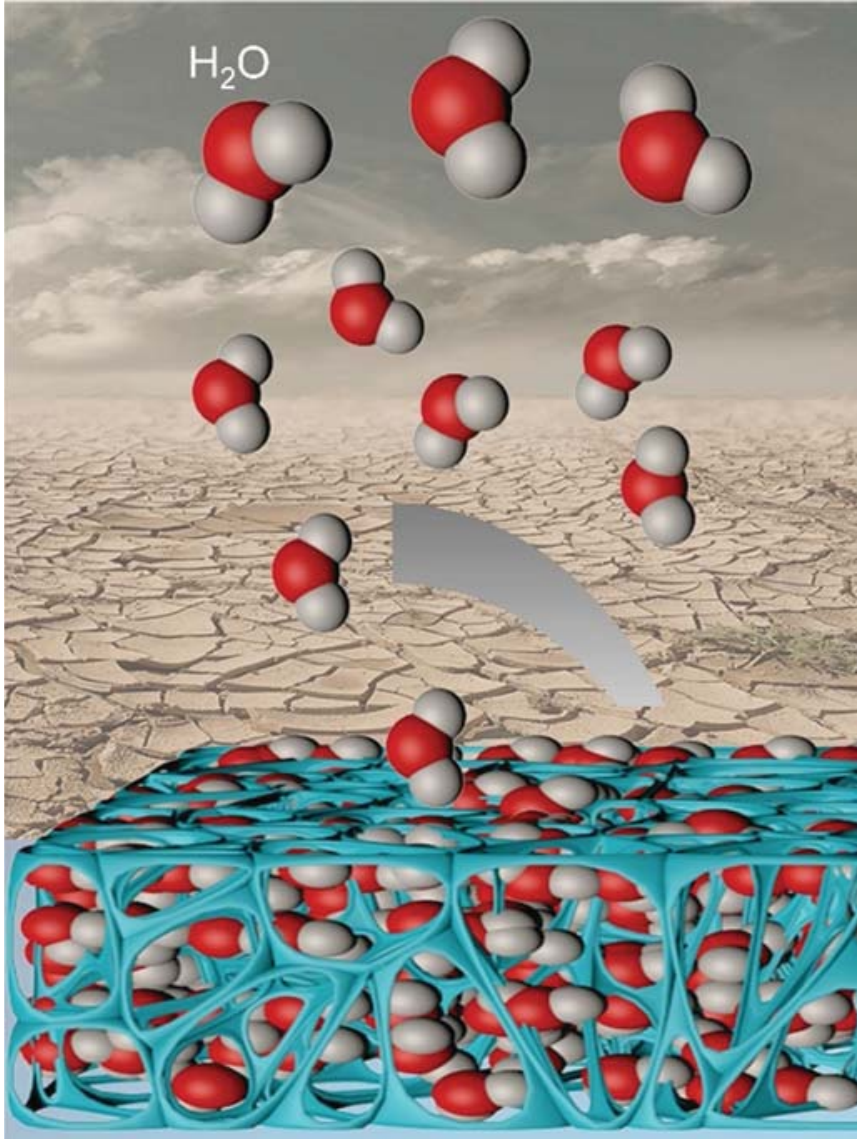

Water 'favourable' porous polymers

Adsorption chillers

Heat pumps

Desiccants

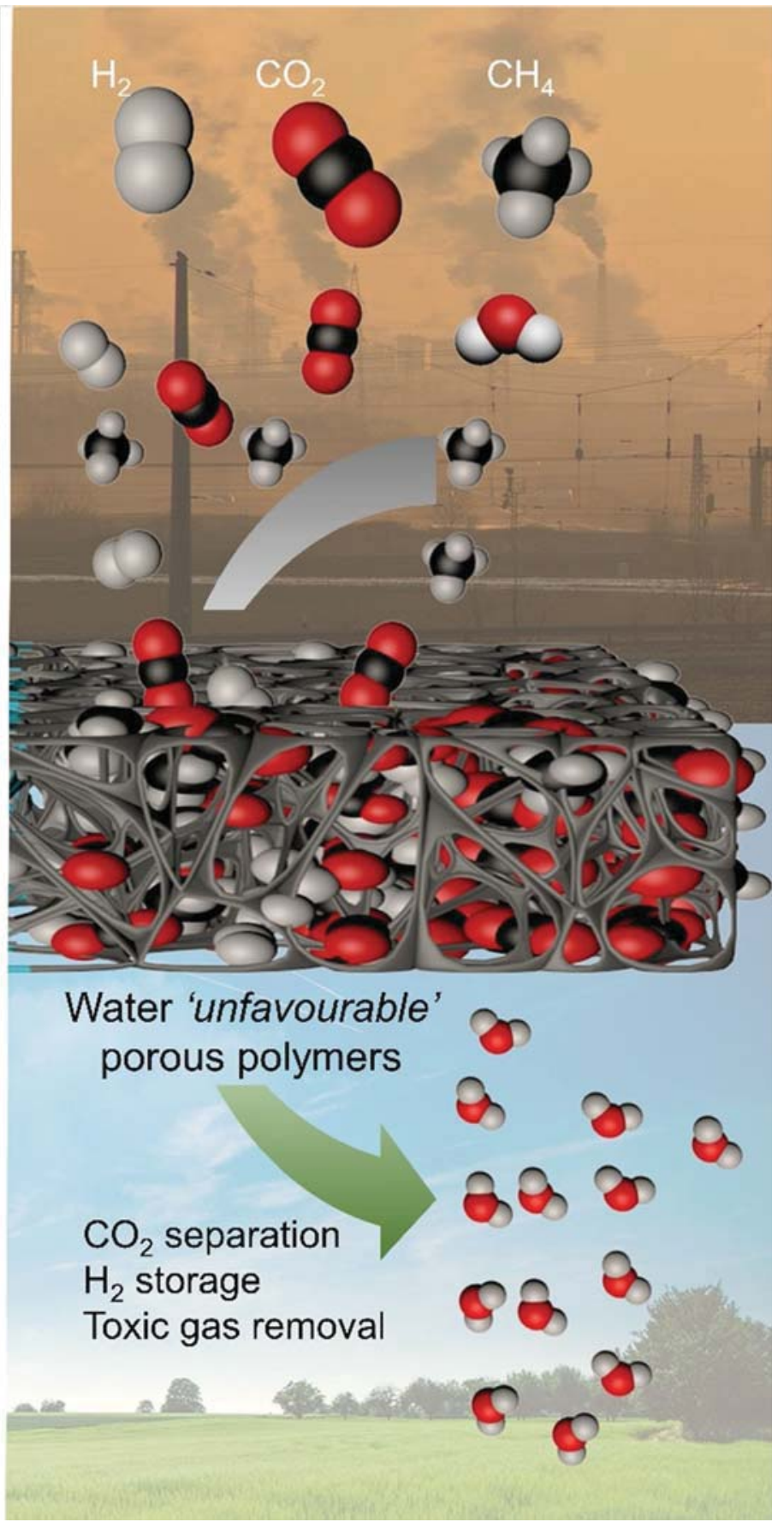


Abstract: Desiccant driven dehumidification for maintaining the proper humidity levels and atmospheric water capture with minimum energy penalty are important aspects in heat pumps, refrigeration, gas and liquid purifications, gas sensing, and clean water production for improved human health and comfort. Water adsorption by using nanoporous materials has emerged as a viable alternative to energy-intensive industrial processes, thus understanding the significance of their porosity, high surface areas, vast pore volumes, chemical and structural features relative to the water adsorption is quite important. In this review article, important features of nanoporous materials are presented, including zeolites, porous carbons, as well as crystalline and amorphous porous organic polymers (POPs) to define the interactions between the water molecules and the polar/non-polar functional groups on the surface of these nanoporous materials. In particular, focus is placed on the recent developments in POPs in the context of water capture as a result of their remarkable stability towards water and wide range of available synthetic routes and building blocks for their synthesis. We also highlighted recent approaches to increase the water sorption capacity of POPs by modifying their structure, morphology, porosity, and chemical functionality while emphasizing their promising future in this emerging area.

\section{Introduction}

Efficient storage of substances can be regarded as the most essential technology that has been developed by humans. Unlike in the past, when the materials were stored by using "large vessels", it became very important in modern science with the advances in nanotechnology to develop ways to store small and light substances in large quantities. Accordingly, porous materials with tunable pore sizes and functionality have received a great deal of attention. In particular, porous materials such as activated carbon, ${ }^{[1]}$ zeolites, $^{[2]}$ metal-organic frameworks (MOFs), ${ }^{[3]}$ covalent organic frameworks (COFs), ${ }^{[4]}$ porous organic polymers (POPs), ${ }^{[5]}$ present extremely high specific surface areas and also the advantage of capturing and storing various types of materials ranging from solid and liquid substances (i.e., nanoparticles, ${ }^{[6]}$ biosynthetic enzymes, ${ }^{[7]}$ oil spills ${ }^{[8]}$ ) to gaseous substances. Gas capture and storage is among the most representative research areas where porous materials have been applied for the last several years. POPs both in crystalline and amorphous forms offer unique advantages owing to their light weight, low cost, high stability, and tunability. The gas capture and separation performance of POPs can be easily altered by varying the organic building blocks or their functional groups. In addition, favorable textural properties of these polymers such as high microporosity (pore size $<2 \mathrm{~nm}$ ) ${ }^{[9]}$ significantly improve the binding affinity towards the guest molecules owing to the fact that multiple binding sites can simultaneously interact with the guests through various noncovalent interactions. Accordingly, POPs have been widely inves-

[a] Dr. Y. Byun, ${ }^{+}$Dr. S. H. Je, ${ }^{+}$Dr. S. N. Talapaneni, ${ }^{+}$Prof. A. Coskun Graduate School of EEWS, Korea Advanced Institute of Science and Technology (KAIST), Daejeon 34141 (Republic of Korea)

[b] Prof. A. Coskun

Department of Chemistry, University of Fribourg

Chemin de Musee 9, Fribourg 1700 (Switzerland)

E-mail:ali.coskun@unifr.ch

$\left.{ }^{[+}\right]$These authors contributed equally to this work.

(10 The ORCID identification number(s) for the author(s) of this article can be found under: https://doi.org/10.1002/chem.201900940. tigated as adsorbents for the storage of small, environmentally significant gas molecules such as carbon dioxide, methane, hydrogen, and toxic gases. More recently, it has also been shown that POPs can act as efficient desiccants to capture moisture from ambient air or under humid conditions. This particular research area is quite important considering the uneven distribution of clean water sources across the world. In principle, POPs can be utilized to capture atmospheric water and its subsequent regeneration by using solar heat can eliminate the geographic limitations for access to clean water. In addition, humidity control is essential for our everyday life. For example, in the hospitals, the risk of infection is directly associated with the humidity levels, that is, low or high humidity can increase infection risks through bacteria or virus. In industrial applications, water capture is critical in the manufacture of moisturesensitive products such as semiconductors, pharmaceuticals, and electric/electronic products. Furthermore, in energy production, a small amount of water could also play a negative role in energy efficiency, particularly in processes such as (1) natural gas purification, ${ }^{[10]}$ (2) flue gas separation, (3) air separation, ${ }^{[11]}$ and (4) biofuel or diesel production. ${ }^{[12]}$ These processes generally contain moisture from ppm levels up to $40 \mathrm{wt} \%$, which should be eliminated for proper operation. Therefore, it is highly important to develop an efficient "humidity controlling agent" that can selectively adsorb moisture under various conditions.

There is tremendous interest in maintaining proper humidity levels in air for the protection of the entire ecosystem. ${ }^{[13]}$ The development of environmentally friendly advanced technologies for the adsorption of water vapor under different conditions coupled with the preparation of novel materials with improved uptake properties, recycling possibilities, and long-term use are enduring tasks. ${ }^{[14]}$ To date, many inorganic adsorbents, namely, metal salts, zeolites, activated alumina, and MOFs have been widely used as moisture adsorbents. The most wellknown and easy-to-use drying agents are metal salts such as $\mathrm{LiBr}$, $\mathrm{LiCl}, \mathrm{KBr}, \mathrm{CaCl}_{2}$, and $\mathrm{MgCl}_{2}$, however, their irreversible water sorption, high solubility in water, and tendency to crystallize at high humidity levels make it difficult to use them as reversible moisture adsorbents. Although there have been several attempts to use metal hydroxides such as $\mathrm{NaOH}, \mathrm{KOH}$, 
$\mathrm{CsOH}$ instead of metal salts, their implementation in actual processes is still difficult as they melt at high humidity levels and lose their adsorption properties. Zeolites and activated alumina are the most widely used materials for dehumidification; however, their thermal regeneration step requires a very high energy input, with temperatures as high as $250-350^{\circ} \mathrm{C} .^{[15]}$ Recently, MOFs have been utilized in water sorption applications. ${ }^{[16]}$ However, the limited availability of water-stable MOFs and their relatively high cost are still important factors to be considered for large-scale applications. In this regard, POPs are promising alternatives for humidity control, owing to their low cost, good physicochemical stability, and relatively lower regeneration temperatures. In this minireview, we will first introduce critical factors for water vapor adsorption and then critically evaluate conventional water adsorbents such as zeolites and activated carbon, and finally focus on POPs. A brief overview of the textural properties and water uptake behaviors for the samples discussed in this work is given in Table 1.

\section{Assessing the stability of desiccants in water}

The hydrolytic stability of a sorbent is the first critical factor that needs to be considered. The most representative methods for determining the water stability of the sorbents include powder X-ray diffraction (PXRD) analysis and nitrogen adsorption isotherms at $77 \mathrm{~K}$ before and after water vapor uptake measurements. However, PXRD is only useful in crystalline materials, such as MOFs, COFs, and nitrogen adsorption isotherms in the most carbon- or silica-based porous materials generally do not show any significant change in their values, hence an appropriate method that is specific to the properties of each material should be used. Alternatively, the stability may be assessed by performing structural analyses such as nuclear magnetic resonance (NMR) spectroscopy and surface area analysis after immersing the adsorbent in water. More recently, it has also been proposed to expose sorbents to high-humidity and temperature conditions as a method to evaluate their stability. Critically, the most important requirement for such a stability measurement is that it needs to be performed under the environment in which the actual adsorbent would be used. For example, in a "single cycle condition", that is, an adsorbent for water/oil separation, the adsorbent may only be stable until the maximum adsorption capacity amount is reached, but in a continuous system such as air separation, flue gas or fuel purification, the structure and performance of the adsorbent must be maintained after several adsorption/regeneration cycles. Many studies try to replicate these conditions at a laboratory level, but it is rather difficult owing to the large number of impurities $\left(\mathrm{SO}_{x}, \mathrm{NO}_{x}, \mathrm{~N}_{2}\right.$, or dust) present in the actual gas mixtures. Therefore, when considering the hydrolytic stability of adsorbents, the physical stability and type of process must be considered along with the maximum adsorption capacities and cyclability.

\section{Water vapor adsorption techniques}

The porous sorbents could be categorized into three groups according to their pore sizes: i) macroporous (50-100 nm), 


\begin{tabular}{|c|c|c|c|c|c|c|c|c|c|c|}
\hline Adsorbents & $\begin{array}{l}\text { BET surface } \\
\text { area }^{[\mathrm{a}]} \\
{\left[\mathrm{m}^{2} \mathrm{~g}^{-1}\right]}\end{array}$ & $\begin{array}{l}\text { Micropore } \\
\text { volume } \\
{\left[\mathrm{cm}^{3} \mathrm{~g}^{-1}\right]}\end{array}$ & $\begin{array}{l}\text { Total pore } \\
\text { volume } \\
{\left[\mathrm{cm}^{3} \mathrm{~g}^{-1}\right]}\end{array}$ & $\begin{array}{l}\text { Average pore } \\
\text { diameter } \\
{[\mathrm{nm}]}\end{array}$ & $\begin{array}{l}\mathrm{H}_{2} \mathrm{O} \\
\text { adsorption }^{[\mathrm{b}, \mathrm{c}]} \\
{\left[\mathrm{mmol} \mathrm{g}^{-1}\right]}\end{array}$ & 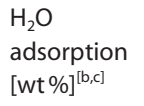 & $\begin{array}{l}\text { Degassing } \\
\text { temperature } \\
{[\mathrm{K}]}\end{array}$ & Note & $\begin{array}{l}\text { Measured } \\
\text { temperature } \\
{[\mathrm{K}]}\end{array}$ & Ref. \\
\hline & \multicolumn{10}{|c|}{ Covalent organic frameworks (COFs) } \\
\hline $\mathrm{AB}-\mathrm{COF}$ & \multicolumn{2}{|l|}{1125} & 0.47 & 1.3 & 22.9 & 41 & vacuum & & 288,298 & [47] \\
\hline trzn-COF & \multicolumn{2}{|l|}{408.5} & 0.21 & 2.3 & 2 & 4 & vacuum & & 298,308 & [48] \\
\hline TpPa-1 & \multicolumn{2}{|l|}{984} & & 1.8 & 24.5 & 44 & 423 & & 298 & [49] \\
\hline TpPa-2 & \multicolumn{2}{|l|}{460} & & 1.5 & 12.5 & 22 & 423 & & 298 & [49] \\
\hline $\mathrm{TpPa} \mathrm{F}_{4}$ & \multicolumn{2}{|l|}{529} & & 1.7 & 10.1 & 18 & 423 & & 298 & [49] \\
\hline $\mathrm{TpPa}-\mathrm{NO}_{2}$ & \multicolumn{3}{|l|}{457} & 1.6 & 30 & 17 & 423 & & 298 & [49] \\
\hline TpBD & \multicolumn{3}{|l|}{341} & 2.4 & 8.1 & 15 & 423 & & 298 & [49] \\
\hline TpBD-Me ${ }_{2}$ & \multicolumn{3}{|l|}{ N/A } & N/A & 7.5 & 14 & 423 & & 298 & [49] \\
\hline $\mathrm{TpBD}-(\mathrm{OMe})_{2}$ & \multicolumn{3}{|l|}{365} & 2.3 & 9.1 & 16 & 423 & & 298 & [49] \\
\hline Tp-azo & \multicolumn{3}{|l|}{942} & 2.7 & 22.7 & 41 & 423 & & 298 & [49] \\
\hline 2,5-DhaTab & \multicolumn{3}{|l|}{ N/A } & N/A & $\mathrm{N} / \mathrm{A}$ & $\mathrm{N} / \mathrm{A}$ & 423 & & 298 & [49] \\
\hline 2,5-DhaTph & \multicolumn{3}{|l|}{1112} & 2 & 24.3 & 44 & 423 & & 298 & [49] \\
\hline 2,3-DhaTph & 659 & & & 2 & 8.5 & 15 & 423 & & 298 & [49] \\
\hline TpPa-1 & 1432 & & & 1.48 & 28.9 & 52 & 273 & & 298 & [50] \\
\hline TpPa-2 & 538 & & & 1.06 & $17.3^{*}$ & $31^{*}$ & 273 & & 298 & [50] \\
\hline $\mathrm{TpPa}-\mathrm{NO}_{2}$ & 850 & & & 1.32 & $27.2^{*}$ & $49^{*}$ & 273 & & 298 & [50] \\
\hline TpBD & 1400 & & & 2.18 & $33.7^{*}$ & 61 & 273 & & 298 & [50] \\
\hline $\mathrm{TpBD}-\mathrm{Me}_{2}$ & 3109 & & & 1.63 & $21^{*}$ & $38^{*}$ & 273 & & 298 & {$[50]$} \\
\hline $\mathrm{TpBD}-\left(\mathrm{NO}_{2}\right)_{2}$ & 769 & & & 1.63 & $21^{*}$ & $38^{*}$ & 273 & & 298 & [50] \\
\hline $\mathrm{TpBD}(\mathrm{OMe})_{2}$ & 1343 & & & 1.63 & $20.8^{*}$ & $37^{*}$ & 273 & & 298 & [50] \\
\hline Tp-Azo & 3038 & & & 2.58 & 27.1 & 49 & 273 & & 298 & [50] \\
\hline TpAnq & 1027 & & & 1.63 & $21.8^{*}$ & $39 *$ & 273 & & 298 & {$[50]$} \\
\hline TpВpy & 2336 & & & 2.42 & 43.5 & 78 & 273 & & 298 & [50] \\
\hline TpTph & 1020 & & & 2.58 & $19.3^{*}$ & $35^{*}$ & 273 & & 298 & {$[50]$} \\
\hline TpTta & 825 & & & 0.86 & $19.3^{*}$ & $35^{*}$ & 273 & & 298 & [50] \\
\hline CE-2 & 588 & 0.155 & 0.47 & 0.78 & $3.9^{*}$ & $6.9^{*}$ & 423 & & 293 & [57] \\
\hline CE-3 & 540 & 0.14 & 0.43 & 0.86 & $3.5^{*}$ & $6.3^{*}$ & 423 & & 293 & [57] \\
\hline bipy-CTF500 & 1548 & 0.64 & 0.71 & 0.8 & $25.1^{*}$ & $45^{*}$ & vacuum & & 298 & [58] \\
\hline pym-CTF500 & 208 & $\mathrm{~N} / \mathrm{A}$ & $\mathrm{N} / \mathrm{A}$ & 0.8 & $12.2^{*}$ & $22^{*}$ & vacuum & & 298 & [58] \\
\hline CTF-a & 2439 & & 1.96 & & 77.2 & 139 & vacuum & & 292.5 & [59] \\
\hline CTF-b & 1179 & & 0.64 & & 31.3 & 56 & vacuum & & 292.5 & [59] \\
\hline CTF-C & 2071 & & 1.36 & & 50.9 & 91.8 & vacuum & & 292.5 & [59] \\
\hline CTF-d & 1683 & & 2.63 & & 41.7 & 75 & vacuum & & 292.5 & [59] \\
\hline CTF-TPC & 1668 & 0.65 & 0.93 & 0.59 & $19.0^{*}$ & $34^{*}$ & 403 & & 293 & {$[60]$} \\
\hline CTF-FL & 773 & 0.31 & 0.39 & 0.5 & $11.7^{*}$ & $21^{*}$ & 403 & & 293 & [60] \\
\hline $\mathrm{Ad} 2 \mathrm{~L} 1$ & 918 & 0.34 & 0.86 & & 15.5 & 28 & 473 & & 293 & [61a] \\
\hline $\mathrm{Ad} 2 \mathrm{~L} 2$ & 1316 & 0.48 & 2.2 & & 8.9 & 16 & 473 & & 293 & [61a] \\
\hline $\mathrm{Ad} 2 \mathrm{~L} 3$ & 747 & 0.28 & 0.45 & & 12.8 & 23 & 473 & & 293 & [61a] \\
\hline Ad3L1 & 1199 & 0.44 & 0.8 & & 23.9 & 43 & 473 & & 293 & [61a] \\
\hline $\mathrm{Ad} 3 \mathrm{~L} 2$ & 1093 & 0.4 & 0.96 & & 21.1 & 38 & 473 & & 293 & [61a] \\
\hline Ad3L3 & 1328 & 0.48 & 0.93 & & 31.1 & 56 & 473 & & 293 & [61a] \\
\hline Ad4L1 & 1617 & 0.61 & 0.9 & & 25.0 & 45 & 473 & & 293 & [61a] \\
\hline Ad4L2 & 1885 & 0.67 & 1.52 & & 38.3 & 69 & 473 & & 293 & [61a] \\
\hline Ad4L3 & 1341 & 0.52 & 0.74 & & 30.0 & 54 & 473 & & 293 & [61a] \\
\hline MM1 & 1800 & 0.67 & 1.11 & & 27.7 & 50 & 473 & $\begin{array}{l}5.1 \text { wt } \% \text { by KTF } \\
\text { method }\end{array}$ & 293 & [61b] \\
\hline MM2 & 1360 & 0.55 & 0.67 & & 24.5 & 44 & 473 & $\begin{array}{l}17.5 \text { wt } \% \text { by KTF } \\
\text { method }\end{array}$ & 293 & [61b] \\
\hline MM3 & 1884 & 0.67 & 1.52 & & 42.3 & 76 & 473 & $\begin{array}{l}1.9 \text { wt } \% \text { by KTF } \\
\text { method }\end{array}$ & 293 & [61b] \\
\hline MM4 & 1407 & 0.54 & 0.78 & & 21.4 & 38 & 473 & $\begin{array}{l}6.3 \text { wt } \% \text { by KTF } \\
\text { method }\end{array}$ & 293 & [61b] \\
\hline $\begin{array}{l}\text { bpim-CTF- } \\
300\end{array}$ & 2.4 & - & & & 6.4 & 11.5 & 423 & & 298 & [63] \\
\hline $\begin{array}{l}\text { bpim-CTF- } \\
400\end{array}$ & 786 & 0.33 & 0.34 & & 17.1 & 30.7 & 423 & & 298 & [63] \\
\hline $\begin{array}{l}\text { bpim-CTF- } \\
500\end{array}$ & 1556 & 0.74 & 0.75 & & 26.8 & 48.2 & 423 & & 298 & [63] \\
\hline
\end{tabular}




\begin{tabular}{|c|c|c|c|c|c|c|c|c|c|}
\hline Adsorbents & $\begin{array}{l}\text { BET surface } \\
\text { area }^{[\mathrm{a}]} \\
{\left[\mathrm{m}^{2} \mathrm{~g}^{-1}\right]}\end{array}$ & $\begin{array}{l}\text { Micropore } \\
\text { volume } \\
{\left[\mathrm{cm}^{3} \mathrm{~g}^{-1}\right]}\end{array}$ & $\begin{array}{l}\text { Total pore } \\
\text { volume } \\
{\left[\mathrm{cm}^{3} \mathrm{~g}^{-1}\right]}\end{array}$ & $\begin{array}{l}\text { Average pore } \\
\text { diameter } \\
{[\mathrm{nm}]}\end{array}$ & $\begin{array}{l}\mathrm{H}_{2} \mathrm{O} \\
\text { adsorption }^{[\mathrm{b}, \mathrm{c}]} \\
{\left[\mathrm{mmol} \mathrm{g}^{-1}\right]}\end{array}$ & $\begin{array}{l}\mathrm{H}_{2} \mathrm{O} \\
\text { adsorption } \\
{[\mathrm{wt} \%]^{[\mathrm{b}, \mathrm{c}]}}\end{array}$ & $\begin{array}{l}\text { Degassing Note } \\
\text { temperature } \\
{[\mathrm{K}]}\end{array}$ & $\begin{array}{l}\text { Measured } \\
\text { temperature } \\
{[\mathrm{K}]}\end{array}$ & Ref. \\
\hline DCBP-CTF-1 & 2437 & 1.41 & 1.48 & & 28.13 & 50.7 & 423 & 293 & [64] \\
\hline \multirow{2}{*}{$\begin{array}{l}\text { F-DCBP-CTF- } \\
1\end{array}$} & 1574 & 0.51 & 1.5 & & 11.3 & 20.3 & 423 & 293 & [64] \\
\hline & \multicolumn{9}{|c|}{ Porous organic polymers (POPs) } \\
\hline CPOP-8 & $1610(430)$ & & 1.71 & 0.63 & $6.7^{*}$ & $12^{*}$ & 393 & 298 & {$[65]$} \\
\hline CPOP-9 & $2440(180)$ & & 2.04 & 0.63 & $24.6^{*}$ & $44^{*}$ & 393 & 298 & [65] \\
\hline CPOP-10 & $1110(650)$ & & 0.76 & 0.63 & $2.2^{*}$ & $4^{*}$ & 393 & 298 & [65] \\
\hline CPOP-11 & 1320 & & 1.13 & $0.61,1.33$ & $1.1^{*}$ & $2^{*}$ & 393 & 298 & [66] \\
\hline CPOP-12 & 1180 & & 1.05 & $0.59,1.31$ & $8.4^{*}$ & $15^{*}$ & 393 & 298 & [66] \\
\hline PSN-3 & 865 & 0.83 & & 0.6 & $3.3^{*}$ & $6^{*}$ & 393 & 298 & [67] \\
\hline \multirow[t]{2}{*}{ MPI-6FA } & 781 & & 0.53 & 0.48 & 4.7 at $80 \%$ & 8.5 at $80 \%$ & 393 & 298 & [68] \\
\hline & & & & & $\mathrm{RH}$ & $\mathrm{RH}$ & & & \\
\hline MPI-BPA & 677 & & 0.39 & 0.53 & $\begin{array}{l}7.4 \text { at } 80 \% \\
\mathrm{RH}\end{array}$ & $\begin{array}{l}13.3 \text { at } \\
80 \% \mathrm{RH}\end{array}$ & 393 & 298 & [68] \\
\hline MPI-BTA & 490 & & 0.53 & 0.53 & $\begin{array}{l}5.8 \text { at } 80 \% \\
\mathrm{RH}\end{array}$ & $\begin{array}{l}10.4 \text { at } \\
80 \% \mathrm{RH}\end{array}$ & - & 298 & [68] \\
\hline KFUPM-1 & 305 & & & 1 & 18.7 & 33.5 & 383 & 298 & [69] \\
\hline NU-POP-1 & 950 & & 0.32 & $0.35-0.8$ & $12.8^{*}$ & $23^{*}$ & - & 298 & [70] \\
\hline OFC-1 & 780 & & 0.54 & & $6.8^{*}$ & $12.2^{*}$ & 423 & 298 & [71] \\
\hline DUT-92 & 720 & & 1.76 & & $4.5^{*}$ & $8.1^{*}$ & 423 & 298 & [71] \\
\hline DUT-92 $\left(\mathrm{NO}_{2}\right)$ & 500 & & 0.44 & & $8.1^{*}$ & $14.5^{*}$ & 423 & 298 & [71] \\
\hline DUT-92 $\left(\mathrm{NH}_{2}\right)$ & 700 & & 0.42 & & $13.7^{*}$ & $24.5^{*}$ & 423 & 298 & [71] \\
\hline DUT-93 & 320 & & 1.02 & & $2.2^{*}$ & $3.9^{*}$ & 423 & 298 & [71] \\
\hline DUT-93 $\left(\mathrm{NO}_{2}\right)$ & 160 & & 0.5 & & $5.4^{*}$ & $9.6^{*}$ & 423 & 298 & [71] \\
\hline DUT-93 $\left(\mathrm{NH}_{2}\right)$ & nonporous & & nonporous & & $9.0^{*}$ & $16.1^{*}$ & 423 & 298 & [71] \\
\hline MOPI-I & 206 & 0.05 & 0.16 & & 13.5 & 24.192 & 383 & 298 & [73] \\
\hline MOPI-II & 644 & 0.17 & 0.32 & & 12.3 & 22.0 & 383 & 298 & [73] \\
\hline MOPI-III & 433 & 0.09 & 0.27 & & 9.0 & 16.1 & 383 & 298 & [73] \\
\hline MOPI-IV & 660 & 0.19 & 0.28 & & 19.5 & 34.4 & 383 & 298 & [73] \\
\hline MOPI-V & 921 & 0.23 & 0.44 & & 7.0 & 12.5 & 383 & 298 & [73] \\
\hline PIN1 & 458 & 0.5 & 0.3 & 0.6 & 8.5 & 15.2 & 423 & 298 & [72] \\
\hline PIN2 & 325 & 0.17 & 0.35 & & 7.0 & 12.5 & 423 & 298 & [72] \\
\hline PIN1_2 & 28 & - & 0.05 & & 3.0 & 5.4 & 423 & 298 & [72] \\
\hline COP-120 & 42 & & 0.15 & & $25.1^{*}$ & $45^{*}$ & 383 & 298 & [74] \\
\hline 2D ep-POP & $852(464)$ & 0.18 & & 0.47 & 22.9 & 41.1 & regeneration at $328 \mathrm{~K}$ & 298 & {$[75]$} \\
\hline 3D ep-POP & 779 (462) & 0.17 & & 0.4 & 22.9 & 41.1 & $373 \mathrm{~K}$ & 298 & [75] \\
\hline EOF-6 (POP) & 1380 & 0.9 & 0.63 & & 19.5 & 35 & 423 & 298 & {$[76]$} \\
\hline EOF-7 (POP) & 1083 & 0.69 & 0.51 & & 4.9 & 8.8 & 423 & 298 & {$[76]$} \\
\hline EOF-8 (POP) & 540 & 0.32 & 0.26 & & 2.0 & 3.6 & 423 & 298 & [76] \\
\hline EOF-9 (POP) & 602 & 0.38 & 0.3 & & 4.9 & 8.8 & 423 & 298 & {$[76]$} \\
\hline Py-PP & & & 0.71 & & 1.1 & 2 & 483 & 298 & {$[77]$} \\
\hline
\end{tabular}

ii) mesoporous (2-50 nm), and iii) microporous $(<2 \mathrm{~nm})$, and they can be further distinguished into six isotherm types based on their nitrogen adsorption isotherms. The detailed description of the isotherm profiles will not be discussed in this review, however, interested readers can refer to the review article on this topic. ${ }^{[17]}$ Here, we primarily focus on the adsorption isotherms to differentiate the hydrophobicity and the hydrophilicity of the adsorbent and how to use these isotherms when evaluating water uptake isotherms.

Hydrophilic adsorbents have naturally strong interactions with water molecules, typically zeolite and silica-based sorbents are classified as hydrophilic. Previously, these characteristics have been pointed out as demerits as they lower the adsorption efficiency of target gases such as $\mathrm{CO}_{2}$ or $\mathrm{CH}_{4}$ owing to competitive binding, but recently they have become great ad- vantages for moisture adsorption. Conversely, although most carbon materials are known to be hydrophobic, in reality, some of these materials could adsorb a large amount of water. From this phenomenon, it is assumed that the moisture adsorption is greatly influenced by the pore volume rather than the nature of the material. Then, how do we actually distinguish between hydrophilic and hydrophobic sorbents? The answer lies in their adsorption isotherms. The water vapor adsorption isotherms can be interpreted in the same way as the traditional gas adsorption isotherms at room temperature. For example, substances that exhibit rapid adsorption at low relative pressures could be considered as hydrophilic materials owing to the strong interactions between water molecules and adsorbents. On the contrary, if the isotherm profile shows nearly no to little adsorption at the low-pressure region, the 
material would be classified as a hydrophobic sorbent. Namely, hydrophilicity is proportional to the slope of the graph at zero loading. The quantitative indexes were proposed by Anderson and Klinowski, ${ }^{[18]}$ Weitkamp et al., ${ }^{[19]}$ and Giaya et al. ${ }^{[20]}$

Various methods to analyze the quantity of adsorbed water vapor have been developed. One of the methods is to measure the change in the weight of the sample at different temperatures. Vapor uptake capacity can be determined simply from the weight difference obtained at room temperature and high temperature $\left(\approx 400^{\circ} \mathrm{C}\right)$. Here, it is assumed that the adsorbed vapor is coming solely from the ambient air. However, when we use oven or thermogravimetric analysis (TGA) instruments, it can be hard to distinguish the types of gases and thus the obtained adsorption values could also include impurities or other adsorbed gases along with water. To account for this effect, degassed adsorbents can be exposed to a humid environment or water vapor during the measurement.

For an accurate uptake measurement, recording adsorption/ desorption isotherms through a standard surface area analysis, that is, Brunauer-Emmett-Teller (BET), is a typical method. In most cases, the isotherm of the adsorbent is investigated at $298 \mathrm{~K}$, and the adsorption amount is plotted as a function of the relative pressure $\left(P / P_{0}=0-1.0\right.$ where $P_{0}$ is the saturated vapor pressure at the given temperature) or relative humidity $(\mathrm{RH}=0-100 \%)$. When the relative pressure is close to 1 , the maximum adsorption amount $\left(\mathrm{cm}^{3}{ }_{22} \mathrm{~g}^{-1}\right.$ of sample) can be determined, which is highly related to pore volume, with the exception of superhydrophobic microporous solids, wherein the water adsorption mechanism is based on liquid water intrusion. ${ }^{[21]}$ In the case of mesoporous materials, capillary condensation occurs as a result of the bottleneck phenomenon, resulting in a difference in the adsorption/desorption curve, called a "hysteresis loop". In addition, the relative pressure at which half of the total water capacity is reached is also another comparable factor to evaluate the hydrophobicity of adsorbents. The units for water adsorption are generally represented as $\mathrm{cm}^{3} \mathrm{~g}^{-1}$ (volume of water adsorbed per gram of adsorbent), which can be converted to wt \% (weight percent of water adsorbed per gram of adsorbent). The isosteric heat of adsorption at zero coverage $\left(Q_{s t}\right)$ is also a good indicator for the hydrophobicity/philicity of sorbents, which will directly affect the required regeneration temperature. The isosteric enthalpy of adsorption can be calculated from the Clausius-Clapeyron equation, given by Equation (1).

$\Delta H=R\left(\frac{\mathrm{d}(\ln P)}{\mathrm{d}\left(-\frac{1}{T}\right)}\right)_{w}$

where $\Delta H, R, P, T$, and $w$ represent the isosteric enthalpy of adsorption, universal gas constant, pressure, temperature, and vapor uptake, respectively.

IUPAC classifies isotherm types for adsorbents that are microporous (type I), nonporous or macroporous (type II, III, and $\mathrm{VI}$ ), or mesoporous (type IV and V). For water vapor sorption, type I isotherms are observed for the strongest adsorbate-adsorbent interactions, which are commonly observed (Figure 1) in strongly hydrophilic materials such as zeolites and some
MOFs with open metal sites. The maximum loadings typically lie at very low relative pressure regions. Type I isotherms are applicable for the water filling as a monolayer on the internal surface of the material. Type II isotherms also show a major adsorption in the low relative pressure region, but through multilayer adsorption on the internal surface of the material. The relatively high adsorbate-adsorbent interactions can be achieved by creating primary active centers. Type III isotherms do not show any identifiable monolayer formation and also the adsorbent-adsorbate interactions are relatively weak. This type of isotherm implies strong hydrophobicity of the pore space. Therefore, the water molecules are clustered around the most favorable sites on the surface of the material. Type IV isotherms are observed for materials that swell until the maximum point for site hydration is reached. The weak interaction between water and adsorbent is also observed for type $\mathrm{V}$ isotherms. Type $\mathrm{V}$ isotherms are typically accompanied by a strong hysteresis loop, which is mainly observed for weakly hydrophobic mesoporous materials that undergo capillary condensation. Among these isotherms, the most commonly observed for water uptake in activated carbon and porous organic polymers are type II, III, IV, V, and the bimodal one as shown in Figure $1 \mathrm{a}$. The adsorption mechanism at each stage is further described in Figure $1 \mathrm{~b}$. The stages I, II, III, and IV represent progressive formation of water clusters, cluster growth and coalescence, micropore filling, and mesopore filling, respectively. In wider pores such as mesopores, adsorbates are required to form a bridge, which necessitates higher chemical potential. For materials with smaller pores such as micropores, the adsorption occurs preferentially in these pores.

\section{Potential applications}

Understanding water adsorption behavior is of prime importance for the design of micro- and nanofluidic devices, water purification systems, steam regenerators, removal of contaminants from humid gas streams, desiccants, aqueous based efficient energy storage and conversion devices, and electrocatalysts as well as in several essential applications such as batteries, supercapacitors, water splitting, hydrogen evolution, and oxygen reduction/evolution reactions. ${ }^{[22]}$

In addition, as water is present everywhere, controlling the humidity levels is significant in many industrial and household applications. For each application, the selection of a proper adsorbent will depend on the desired temperature and humidity ranges as shown in Figure 2. ${ }^{[23]}$ For general public buildings such as airport terminals and office buildings, comfortable temperature and humidity levels fall between $21-23^{\circ} \mathrm{C}$ and 20-30\% RH, respectively. For libraries, different humidity and temperature conditions are required depending on specific areas such as archival (35\% RH), art storage (50\% RH). Humidity control is essential in hospital buildings where the risk of infection is directly associated with human health. Humidity and temperature can also affect the quality of final products in manufacturing. Pharmaceutical products involving compressing and coating tablets, manufacturing ampules, and packing medicines require a temperature of $24^{\circ} \mathrm{C}$ and humidity range 

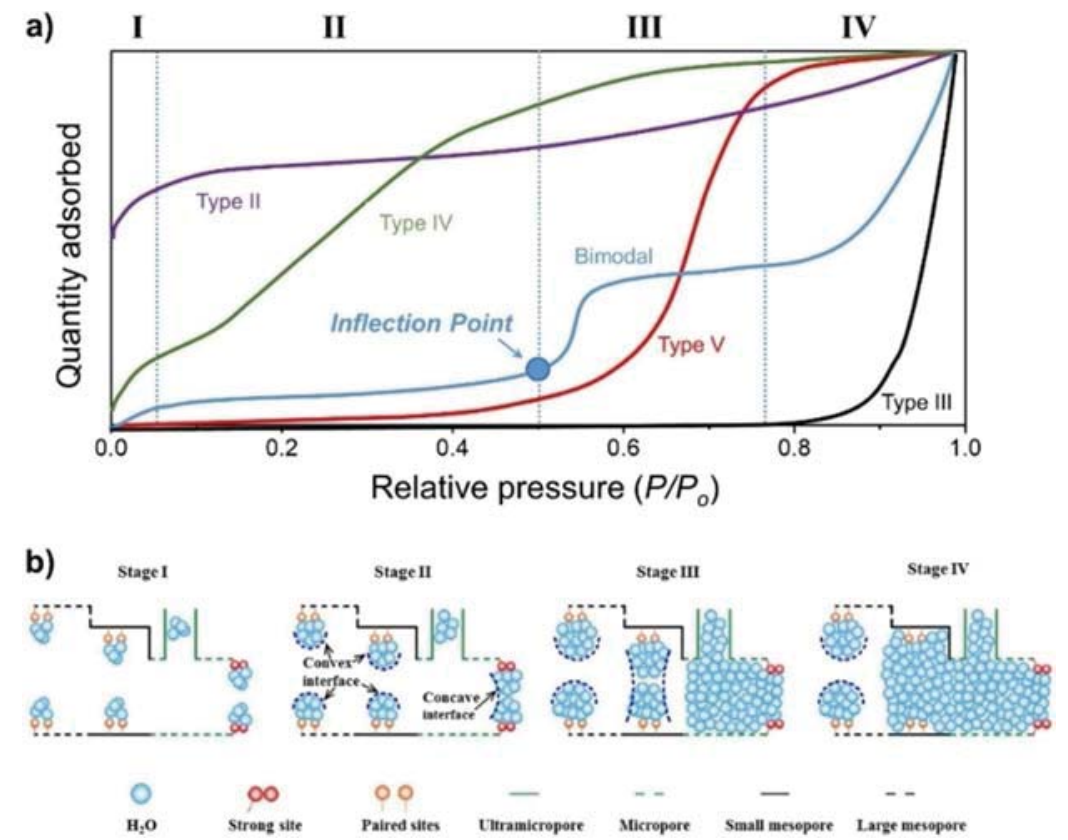

Figure 1. (a) Water vapor adsorption isotherm types according to the IUPAC classification. (b) Mechanism of water sorption in each stage. Reprinted from Ref. [30].

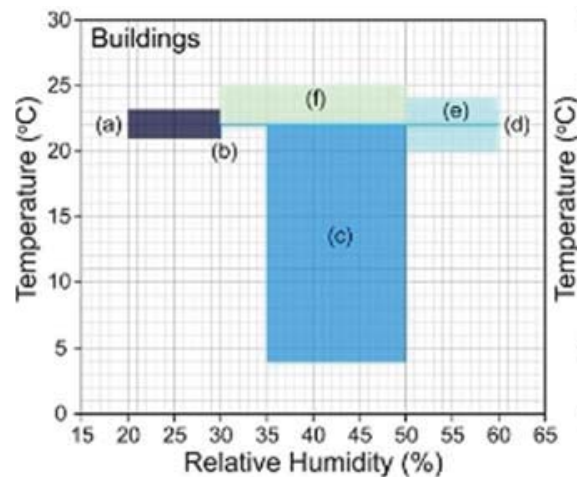

$\begin{array}{ll}\text { - (a) General public buildings - } & \text { (d) Hospitals (clinical ares) } \\ \text { - (o) Resiences } & \text { (e) Hospitals (surgical areas) }\end{array}$

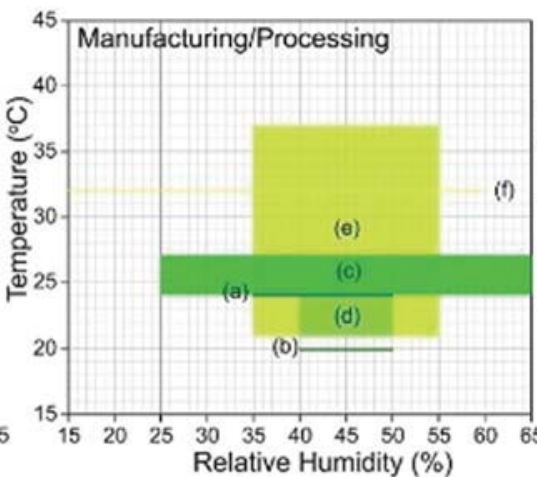

- (a) Pharmacoutcal

- (b) Semiconductor

- (c) Plastic

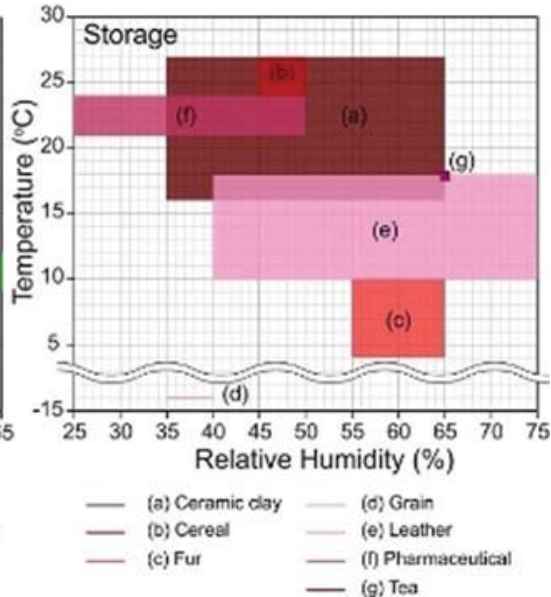

Figure 2. Plots of required temperature and relative humidity levels for different applications such as buildings, manufacturing or processing, and storage.

between $35-50 \% \mathrm{RH}$. The assembly of semiconductors requires a specific temperature of $20^{\circ} \mathrm{C}$ and humidity between $40-50 \% \mathrm{RH}$. Specific conditions are also required to maintain the product quality and freshness during storage. The required conditions for storing tea are $18^{\circ} \mathrm{C}$ and $65 \% \mathrm{RH}$ whereas grain storage requires lower temperature $\left(-14^{\circ} \mathrm{C}\right)$ and humidity (35$40 \% \mathrm{RH})$. In desert and arid regions where water scarcity is a serious issue, the day-time humidity is as low as approximately $10 \%$ with temperatures of $30-40^{\circ} \mathrm{C}$ and the night-time humidity level is approximately $40 \% \mathrm{RH}$ with temperatures in the range $15-25^{\circ} \mathrm{C}$. These listed applications are some examples where water sorption is essential. Optimum water sorption is expected to be achieved by using "water favorable desiccants" where hydrophilic desiccants could effectively adsorb atmospheric water.
One of the widely known industrial applications taking advantage of "water favorable desiccants" is desiccant-driven air conditioning or refrigeration systems. ${ }^{[13 d]}$ Unlike conventional refrigeration or air-conditioning systems, the desiccant-driven systems do not involve hydrochlorofluorocarbon or hydrofluorocarbon refrigerants, which are considered as the main cause of ozone layer depletion. In an adsorption chiller, desiccant materials simply remove heat by evaporating liquid refrigerants such as water. The desired desiccants should possess high water uptake capacities and low regeneration temperatures. On the other hand, some applications require "non-water favorable adsorbents" where hydrophobic or slightly hydrophilic adsorbents selectively adsorb target molecules against water. In these applications, water molecules generally act as contaminants as in post-combustion $\mathrm{CO}_{2}$ capture. 
POPs have been primarily studied in the context of carbon capture. The increasing $\mathrm{CO}_{2}$ levels in the atmosphere originating from anthropogenic $\mathrm{CO}_{2}$ emissions is a global concern owing to its major contribution to global warming. In this regard, the development of new materials for $\mathrm{CO}_{2}$ capture and separation has received a great deal of attention. Naturally, several studies have focused on selective capture of $\mathrm{CO}_{2}$ against water as flue gas mixtures consist of $\mathrm{N}_{2}(75-76 \%), \mathrm{CO}_{2}$ (15-16\%), and $\mathrm{H}_{2} \mathrm{O}(5-7 \%)$. ${ }^{[24]}$ Water can compete with $\mathrm{CO}_{2}$ for adsorption sites, thus generally leading to a significant decrease in $\mathrm{CO}_{2}$ uptake capacity. In this regard, ideal materials should have high thermal and hydrolytic stabilities as well as low affinity towards water vapor. It should, however, be noted that the simultaneous realization of hydrophobicity and $\mathrm{CO}_{2}$ philicity is a challenging task and requires fundamental understanding of the interaction of water and $\mathrm{CO}_{2}$ molecules with the sorbent.

In addition to $\mathrm{CO}_{2}$, the emission of volatile organic compounds (VOCs) has also increased from industrial processes and from domestic consumption. Although the amount of VOCs in the atmosphere is lower than $\mathrm{CO}_{2}$, their lifetime is substantially higher owing to their high stability. Moreover, because of their high vapor pressures and low boiling points, VOCs can be emitted easily into the atmosphere, acting as air pollutants and toxic chemicals. For any sorption application, the adsorbent can be exposed to ambient air and the effectiveness of the sorbent highly depends on the humidity of the surrounding environment. For example, water clusters can form around the pore with active sites and block the adsorption of VOCs. Therefore, understanding the behavior of sorbents under humid conditions along with their affinity towards water is a critical task to improve their performance.

\section{Water Adsorption on Zeolites and Porous Carbon Materials}

Water uptake in nanoporous inorganic materials such as zeolites, zeo-type materials, mesoporous silica, and activated alumina has been considered as an important field of research because of their high adsorption capacity, high water selectivity at various concentrations, and their usage in clean energy systems such as electric dehumidifiers, adsorption-driven heat exchangers, and adsorption-based heat pumps. ${ }^{[13 b]}$ Unique hydrophilic properties coupled with favorable textural parameters such as high specific surface area and large pore volume render zeolites as attractive candidates for water adsorption in addition to their classical applications as ion-exchangers, molecular sieving, and catalysis. ${ }^{[14,25]}$ Aluminum-containing microporous zeolites show type I water sorption isotherms, indicating their high affinity towards water at low partial pressures. ${ }^{[26]}$ The selectivity and water uptake capacity of the zeolites depend highly on their framework type, pore structure, the presence of hetero-metals ( $\mathrm{Al}, \mathrm{Ti}, \mathrm{Sn}, \mathrm{Zr}$, etc.) and their amounts, extra-framework cations, and the distribution of silanol $(\mathrm{Si}-\mathrm{OH})$ groups, which can interact with water molecules through hydrogen-bonding interactions. ${ }^{[27]}$ Evidently, three water molecules can adsorb onto a single silanol group. Minto- va et al. ${ }^{[14]}$ have recently reviewed the water adsorption capacity of functional zeolite materials with respect to their hydrophilicity, porosity, chemical and structural features. Tatlier et al. ${ }^{[28]}$ have investigated the relationship between the theoretically accessible surface area and pore volume for water uptake, pore size, types of secondary building units, and fractal dimensions of zeolites with their experimentally measured water uptake capacities.

The unique structural features of water molecules at the interface of hydrophobic carbon nanostructures led to complex structures owing to the weak hydrogen-bonding interactions compared with those of hydrophilic surfaces and bulk water. ${ }^{[29]}$ Hydrophobic nanoporous carbon materials with and without heteroatom doping have been widely studied for water adsorption at low pressures owing to their high water adsorption capacity at low humidity and easy regeneration. ${ }^{[30]}$ The water adsorption isotherms of porous carbon materials show very low adsorption at $P / P_{0}<0.3$, which is characteristic of a hydrophobic surface, followed by a steep uptake at partial pressures between 0.3 and 1.0, depending on the type of porous structure and functional groups on the surface. Adsorption isotherms of water vapor in most of the porous carbon materials exhibit hysteresis loops with varying magnitudes and shapes depending on the pore aperture size of the nanocarbons. In general, both adsorption and desorption isotherms of water in ultramicroporous carbon materials with pore sizes below $0.7 \mathrm{~nm}$ follow the same profile, which results in the absence of a hysteresis loop. Upon increasing the pore diameter of porous carbons $(>0.7 \mathrm{~nm})$, a hysteresis loop appears at partial pressures between 0.3 and 1.0. ${ }^{[30]}$

Tao et al. ${ }^{[31]}$ demonstrated water adsorption at 298, 308, and $318 \mathrm{~K}$ in the nanospaces of double-walled carbon nanotubes (DWCNTs) and heat-treated double-walled carbon nanotubes (HT-DWCNTs) with surface areas of 510 and $350 \mathrm{~m}^{2} \mathrm{~g}^{-1}$, respectively. Figure 3 a shows the water adsorption isotherms measured for DWCNTs and HT-DWCNTs. The adsorption profiles are S-shaped, suggesting two types of pore filling mechanism at two distinct adsorption steps of $P / P_{0}=0.3$ to 0.65 and for $P / P_{0}$ $=0.65$ to approximately 1 . The total pore volumes determined from the amount of adsorbed water at $318 \mathrm{~K}$ near saturation $\left(P / P_{0}=0.99\right)$ for DWCNTs and HT-DWCNTs and were found to be 0.18 and $0.10 \mathrm{~cm}^{3} \mathrm{~g}^{-1}$, respectively. Ohba evaluated the formation of ice-like water clusters within the internal hydrophobic nanospace of CNTs with different inner diameters by using $\mathrm{X}$-ray diffraction and molecular simulation analysis (Figure $3 b) .{ }^{[32]}$ As depicted in Figure $3 c$ and $d$, the water molecules in CNTs with a diameter of $1 \mathrm{~nm}$ had fewer hydrogen bonds than bulk water under ambient conditions. However, water molecules formed ice-like nanoclusters $(0.8-3.4 \mathrm{~nm})$ even under ambient conditions in CNTs with diameters of 2 and $3 \mathrm{~nm}$ because of strong intermolecular hydrogen-bonding interactions. These results further indicate that $0.8 \mathrm{~nm}$ sized clusters are the fundamental units of water assemblies. Kaneko et al. $^{[31]}$ demonstrated the dynamics of water adsorption in carbon nanotubelites through nanogates. They observed that water molecules can enter into a nanohorn through a nanogate with a pore aperture of $0.5 \mathrm{~nm}$ on the wall of nanohorn. 


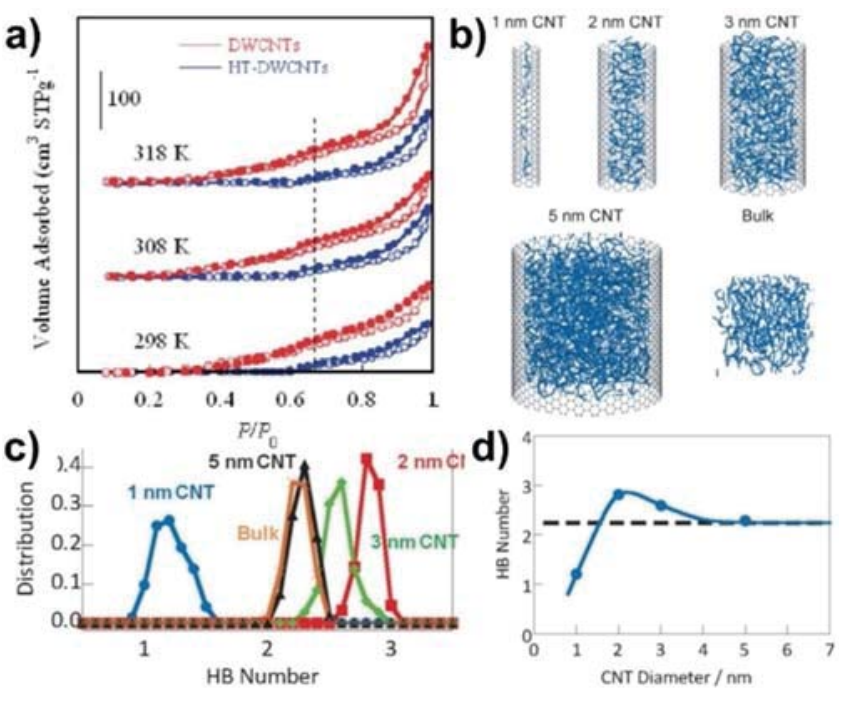

Figure 3. (a) Water adsorption isotherms of double-walled carbon nanotubes (DWCNTs) and heat-treated DWCNTs (HT-DWCNTs) at different temperatures. (b) HRMC simulations of hydrogen bonds of the water in the CNTs and bulk water. (c) Hydrogen bond number distribution of water molecules confined in the CNTs and bulk water. (d) Mean hydrogen bond number relative to the CNT diameter. The dashed line shows the hydrogen bond number in bulk water. Reprinted from Refs. [31] and [32], respectively.

The kinetics of this phenomenon are much slower than "normal" water adsorption, as the water nanoclusters have to form from the water nanochains in order to enter into the nanogates of carbon nanotubelites. ${ }^{[33]}$ Itami et al. ${ }^{[34]}$ have explored the water adsorption properties of a new class of cycloparaphenylene ([12]CPP) carbonaceous porous solids with the uniform structure of 12 benzene molecules linked together. The adsorption/desorption isotherms of $\mathrm{H}_{2} \mathrm{O}$ on [12]CPP has been measured at $298 \mathrm{~K}$. Almost no adsorption was observed up to a relative pressure of $P / P_{0}=0.75$, then a sudden uptake occurred up to $P / P_{0}=1.0$. In the desorption process, no distinct hysteresis loop was observed. The water sorption isotherms indicate the adsorption of water molecules on small nonpolar pore surfaces.

Sullivan et al. ${ }^{[22 a]}$ reported the water uptake behaviors of Novoloid-based activated carbon fiber cloth (ACFC), Calgon BPL granular activated carbon (GAC), Calgon Zorflex ${ }^{\mathrm{TM}}$ activated carbon cloth, military ASZM-TEDA GAC, and electrospun activated carbon nanofibers (ACnF). They concluded that the hydrogen-treated porous Novoloid-based ACFC was more hydrophobic and exhibited a wide hysteresis loop compared with other tested activated carbons. Nakamura et al. ${ }^{[35]}$ also studied the effect of water adsorption with respect to the pore width $(w)$ and equilibration time by using three pitch-based activated carbon fibers (ACFs) (AD'ALL Co.) and two kinds of phenolresin-based ACFs (Kurare Co.). The adsorption isotherms of porous carbons with a pore size of $1.1 \mathrm{~nm}$ show wide hysteresis loops and longer equilibration times ranging from $5 \mathrm{~min}$ to $16 \mathrm{~h}$. The hydrophobic micropores of about $1 \mathrm{~nm}$ in width resulted in an indefinite adsorption hysteresis loop owing to the metastable structure formation of water molecules on the adsorption branch. Importantly, water molecules cannot form the metastable structures on the pore walls in cases where the sizes of the pores are less than the critical pore width of $0.6 \mathrm{~nm}$, thus giving hysteresis-free adsorption isotherms. Horikawa et al. ${ }^{[36]}$ studied the water adsorption hysteresis and their descending scanning curves on a highly graphitized thermal carbon black, Carbopack F, and a highly ordered mesoporous carbon, Hex, with hexagonal shaped pores. The hysteresis loop of the water isotherm for Hex shows three steps: (1) adsorption of water molecules onto the functional groups presented at the junctions between adjacent basal planes of graphene layers; (2) water clusters grown around the functional groups; and (3) formation of larger clusters by bridging of adjacent small water clusters, followed by complete pore filling of the mesopores. Whereas, the hysteresis for Carbopack $\mathrm{F}$ spans a wide range in the relative pressure range of 0 and 0.95 . The hysteresis loop of Carbopack F extends over a very wide pressure range and the loop is larger at the point when the descent starts from a higher loading. Thommes et al. ${ }^{[37]}$ have studied the water adsorption in representative ordered mesoporous materials such as CMK-1, CMK-3, and CMK-8 (mesoporous carbons prepared from MCM-48, SBA-15, and KIT- 6 silica templates). The results suggest that the water adsorption mechanism in the hydrophobic mesoporous carbons is similar to the water cluster formation mechanism suggested for the other carbon nanomaterials including carbon nanotubes and microporous carbon materials. Pore filling of water vapor into the nanospace of mesoporous carbons does not resemble the conventional condensation of wetting of fluids such as argon and nitrogen. However, the effect of temperature on the water evaporation in the highly ordered mesoporous carbons is similar to the capillary evaporation step observed for nitrogen and argon. These observations further prove that the depicted hysteresis is due to the differences in pore filling and emptying mechanisms.

Lodewyckx investigated the kinetics of the adsorption of water vapor on activated carbon both theoretically and experimentally. ${ }^{[38]}$ The experimental data showed the existence of two types of adsorption mechanisms: a rather fast one and a very slow one. The slow kinetics could be explained by the formation of water nanochains in the ultramicropores $(<0.7 \mathrm{~nm})$ present in the activated carbon, similar to the carbon nanotubelites. LeVan et al. ${ }^{[39]}$ and Do et al. ${ }^{[40]}$ have separately described a new equation for water adsorption equilibria on activated carbon. The model is consistent with Henry's law at low loadings and it depicts the full range of isotherms with high accuracy by using a small number of parameters. They have used this model for water adsorption equilibrium data on different types of carbons including ACF activated carbons, NC100, BPL, polymeric type E, PVDC, and UO3-1, which have large differences in surface area, surface chemical properties, and pore structure. The commonly observed hysteresis for these activated carbons is attributed to the slow relaxation of water clusters within the micropores.

Kumar et al. ${ }^{[22 \mathrm{~b}]}$ studied water adsorption on nitrogen-doped carbons by using Monte Carlo simulations (Figure 4), wherein they used model carbon structures doped with graphitic- $N$ and pyridinic-N. Figure $4 \mathrm{~b}$ shows the adsorption of water mol- 
a)

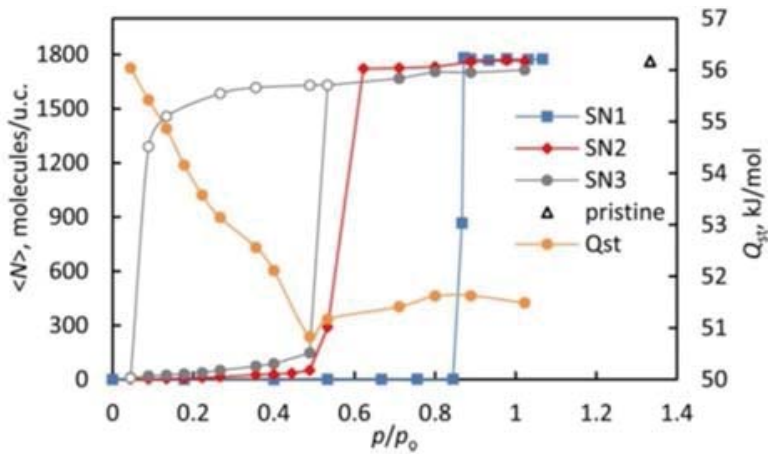

b)
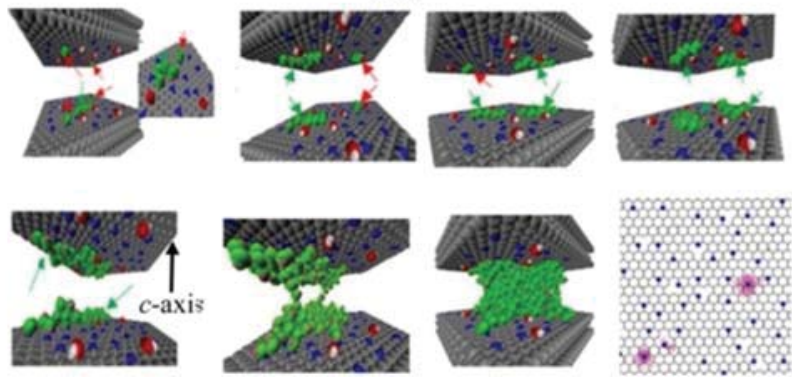

Figure 4. (a) Water vapor adsorption isotherms and the isosteric heat of adsorption in nitrogen-doped carbon prototypes. (b) A series of snapshots showing the equilibrium adsorption of water on nitrogen-doped carbons at different relative pressures and the accumulation of water molecules on one side of the wall (red arrows show the nucleation sites, green arrows correspond to 1D/2D water nanoclusters). Reprinted from Ref. [22].

ecules onto the $\mathrm{N}$-doped carbon at different relative pressures of $P / P_{0}=0.044,0.088,0.177,0.222$, and 0.266 . In particular, at $P / P_{0}=0.044$ and 0.088 , they observed that the water molecules favorably adsorbed onto the $\mathrm{N}$ atoms (Figure $4 \mathrm{~b}$ ) through hydrogen-bonding interactions on both sides of the pore wall. The authors also showed the formation of $1 D$ or $2 D$ water nanoclusters over nitrogen atoms prior to the pore filling. In these materials, the graphitic nitrogen atoms retain the $\mathrm{sp}^{2}$ planar structure of graphene. Weber et al. ${ }^{[41]}$ studied the water vapor adsorption on microporous carbons and nitrogen-enriched microporous carbons prepared through the carbonization of coconut shell and modification with formamide. All the carbon materials studied in this work showed type $\mathrm{V}$ water vapor adsorption isotherms, indicating weak gas-solid interactions especially at low relative pressure $\left(P / P_{0}<0.2\right)$ range, wherein a very low uptake of water is observed. Steady-state water cluster growth was observed, which was associated with the steep increase in water uptake at $P / P_{0}=0.4-0.7$ in the microporous carbons. The steeper part of the isotherm for the $\mathrm{N}$ enriched sample is observed at a lower relative pressure range compared with undoped microporous carbon. Among the materials studied, nitrogen-modified microporous carbons registered with high water uptake capacity of $1.46 \mathrm{mmolg}^{-1}$ at $298 \mathrm{~K}$ owing to the effect of nitrogen enrichment, whereas unmodified microporous carbons showed a water uptake capacity of $1.01 \mathrm{mmol} \mathrm{g}^{-1}$ under identical experimental conditions. Ohba et al. ${ }^{[42]}$ used pitch-based activated carbon fibers (ACFs; Ad'all Co.) with hydrophobic surface and a narrow pore size distribution to examine the mechanism of water vapor adsorption within the hydrophobic carbon micropores. This study was performed by using stabilization energy calculations and evaluation of the molecular assemblies of water formed during adsorption and desorption to clarify the physical reason for the occurrence of adsorption hysteresis in the case of hydrophobic micropores (pore width $=0.5-1.5 \mathrm{~nm}$ ). Figure 5 a shows the adsorption isotherms of water vapor at $303 \mathrm{~K}$ on hydrophobic activated carbon fibers with different average pore sizes. The adsorption of water vapor was not observed (Figure 5 a) below a threshold pressure of water vapor, but significant adsorption occurs above this point for each sample. The threshold pressure increases with the widening of average pore size in ACFs. The hysteresis loop size increases with an in-
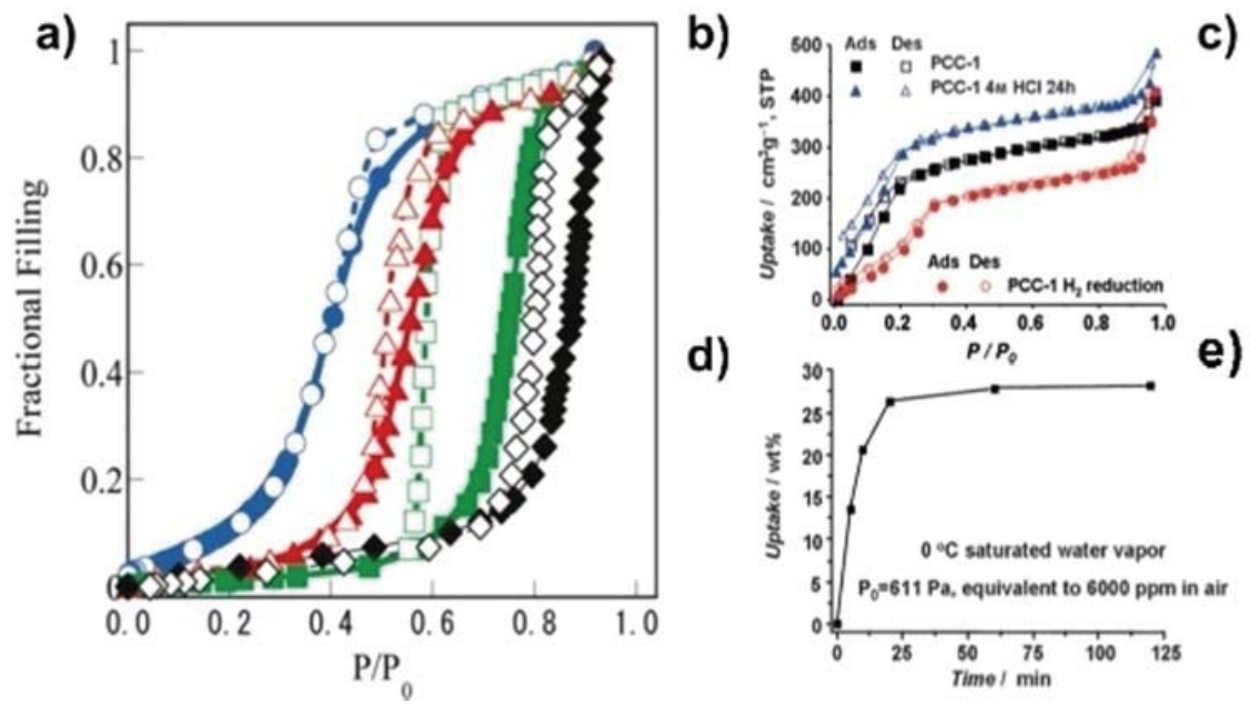

Extended hydrogen bonding networks

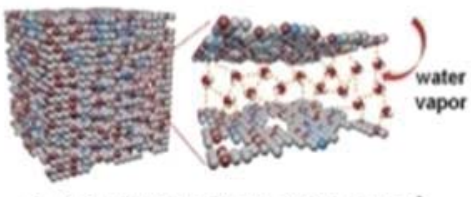

Surface utilization: 7 water molecules/ $\mathrm{nm}^{2}$ Volume utilization: 13 water molecules/ $\mathrm{nm}^{3}$

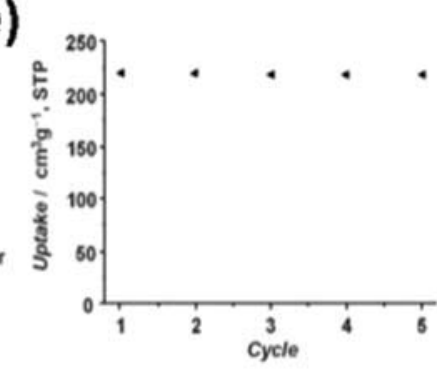

Figure 5. (a) Adsorption isotherms of water at $303 \mathrm{~K}$ for ACFs with average pore diameters of 0.7 (circles), 0.9 (triangles), 1.1 (squares), and $1.3 \mathrm{~nm}$ (diamonds). (b) Water adsorption performance of PCC-1 at 298 K. (c) Schematic representation of low-pressure water adsorption in the PCC carbon micropores by hydrogen bonding between water molecules as well as the water phase and carbon pore walls, respectively. (d-e) Time-dependent water sorption and cycling performance of PCC-1 carbon. Reprinted from Refs. [42] and [43], respectively. 
crease in average pore diameter of up to $1.1 \mathrm{~nm}$. The adsorption and desorption pressures were shown to increase with the widening of average pore diameter. The hysteresis of water adsorption indicates that the adsorption or desorption (or both) path is in a metastable state.

Kaskel et al. ${ }^{[43]}$ investigated the water uptake performance of porous carbon cuboids (PCCs) incorporating $14 \mathrm{wt} \%$ nitrogen and $25 \mathrm{wt} \%$ oxygen with unusual hydrophilic properties, over which the synergistic effects between surface heterogeneity and micropore architecture resulted in a water uptake capacity up to $9.82 \mathrm{mmol} \mathrm{g}^{-1}$ at $P / P_{0}=0.2$ and $398 \mathrm{~K}$ ( $20 \%$ relative humidity or $6000 \mathrm{ppm}$ ) as shown in Figure $5 \mathrm{~b}$. The microporosity of the PCC was verified by a type I nitrogen adsorption isotherm with a large uptake of $\mathrm{N}_{2}$ at low relative pressures. The BET surface area, total pore volume, and pore diameter of PCC were found to be $826 \mathrm{~m}^{2} \mathrm{~g}^{-1}, 0.45 \mathrm{~cm}^{3} \mathrm{~g}^{-1}$, and $7.6 \AA$, respectively. Remarkably, as shown in Figure $5 c$, it was calculated that 13 and 7 water molecules are trapped per $\mathrm{nm}^{3}$ of micropore volume and per $\mathrm{nm}^{2}$ of surface area of PCC-1, respective$l y$, demonstrating the high efficiency of heterogenized microporosity as a " $\mathrm{H}_{2} \mathrm{O}$ reservoir". The water vapor uptake performance of PCCs outperformed all of the representative materials including commercial BPL activated carbon, carbon nanotubes, carbide-derived carbon, nitrogen-doped carbon nanofibers, O-enriched porous carbons, and synthetic carbons, benefitting from properties such as defined morphology, narrow pore size distribution, and high heterogeneity. The high water uptake capacity of PCC is explained on the basis of the presence of the large number of hydrogen bonds between the doped carbon surface and water molecules, which stabilizes the water phase by forming an extended intermolecular hydrogen-bonding network. Sun et al. ${ }^{[44]}$ engineered PCC material with tightly anchored cobalt/cobalt oxide nanoparticles (PCC$\mathrm{CoOx}$ ) through post-functionalization by the dispersion of $\mathrm{CoCl}_{2}$ in solution followed by pyrolysis. SEM and TEM images of PCC-CoOx revealed that the uniform $\mathrm{CoO}$ nanoparticles anchored on hierarchical carbon cuboids, which are randomly aggregated and overlapped with each other, with a rough surface and rich macropores even after $\mathrm{Co} / \mathrm{CoO}$ loading, demonstrating its excellent structural stability. The PCC-CoOx sample showed superior hydrophilic properties with a high water uptake capacity of $6.7 \mathrm{mmolg}^{-1}$ at a relative humidity of $20 \%$ and $25^{\circ} \mathrm{C}$. Hydrophilic ordered mesoporous carbon (HOMC) with an ordered arrangement of uniformly sized mesopores was synthesized by a solvent-free nanocasting approach conducted in a planetary ball mill by using silica spheres as a structural template. ${ }^{[45]}$ Stemming from the synergistic effect of uniformly dispersed $34 \mathrm{wt} \%$ heteroatoms (nitrogen and oxygen) and the highly ordered mesoporous structure, high specific surface area $\left(>1000 \mathrm{~m}^{2} \mathrm{~g}^{-1}\right)$, and large pore volume $\left(>1.2 \mathrm{~cm}^{3} \mathrm{~g}^{-1}\right)$, the apparent water contact angle of the material is $0^{\circ}$-an unprecedented value for carbon materials. Hao et al. ${ }^{[46]}$ prepared hydrophilic, nonprecious metal, nitrogendoped carbon materials such as Fe/N_1/3.2, Fe/Cu/N_1.3/1/8, and $\mathrm{Cu} / \mathrm{N} \_1 / 4$ with surface composition contents of $74.7,14.3$, and $10.33 \%$ for C, N, and O, respectively. They all exhibited relatively good hydrophilic properties, with the water uptake ca- pacities of 5.37, 5.38, and $5.96 \mathrm{mmol} \mathrm{g}^{-1}$ at $P / P_{0}=0.3$ and $298 \mathrm{~K}$ for Fe/N_1/3.2, Fe/Cu/N_1.3/1/8, and $\mathrm{Cu} / \mathrm{N}_{-} 1 / 4$, respectively.

\section{Tailored Porous Organic Polymers as Desic- cants}

\section{Crystalline porous organic polymers as desiccants}

\section{Covalent organic frameworks (COFs)}

COFs are crystalline polymers ${ }^{[4]}$ composed of light elements (B, $\mathrm{C}, \mathrm{N}, \mathrm{O}, \mathrm{Si}$ ) linked together by strong covalent bonds. COFs offer high surface areas and structural tunability by simply varying the nature of the monomeric units. These unique properties of COFs render them as an excellent choice for next-generation adsorbents. The most common COF formation reactions include boronate/boroxine $(B-O)$, imine $(C=N)$ linkages. The reversible nature of these reactions promotes the crystallinity of the resulting frameworks. Although this reversibility is essential for the crystallinity, it naturally renders the resulting frameworks moisture sensitive, which limits the application of these materials to dry gas capture, photovoltaics, and energy storage. The synthesis of water-stable COFs incorporating azine linkages, azine-benzene-COF (AB-COF) and azine-triformylphloroglucinol-COF (ATFG-COF), was reported by Lotsch and co-workers. ${ }^{[47]} \mathrm{AB}-\mathrm{COF}$ and ATFG-COF were synthesized by using 1,3,5-triformyl benzene and 1,3,5-triformyl-phloroglucinol as shown in Figure 6. The hydroxyl $(-\mathrm{OH})$ group in ATFG-COF underwent tautomerization and the authors successfully proved the coexistence of two tautomeric forms. AB- and ATFG-COF exhibited high microporosity with BET surface areas of 1125 and $520 \mathrm{~m}^{2} \mathrm{~g}^{-1}$, and pore volumes of 0.47 and $0.50 \mathrm{~cm}^{3} \mathrm{~g}^{-1}$, respectively. The volumetric water uptake performances of each azine COFs are shown in Figure 7. At $P / P_{0}=$ 0.9 , maximum water uptake capacities for AB-COF and ATFGCOF were found to be 41 and $25 \mathrm{wt} \%$, respectively, featuring
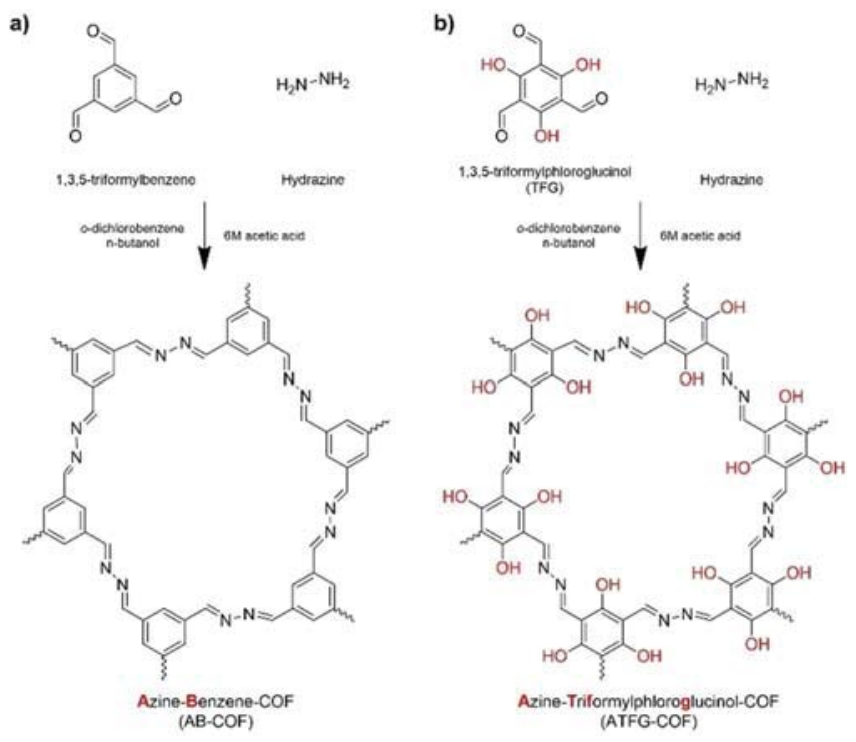

Figure 6. Schematic representation of the synthesis of AB-COF and ATFGCOF. Reprinted with permission from Ref. [47]. 

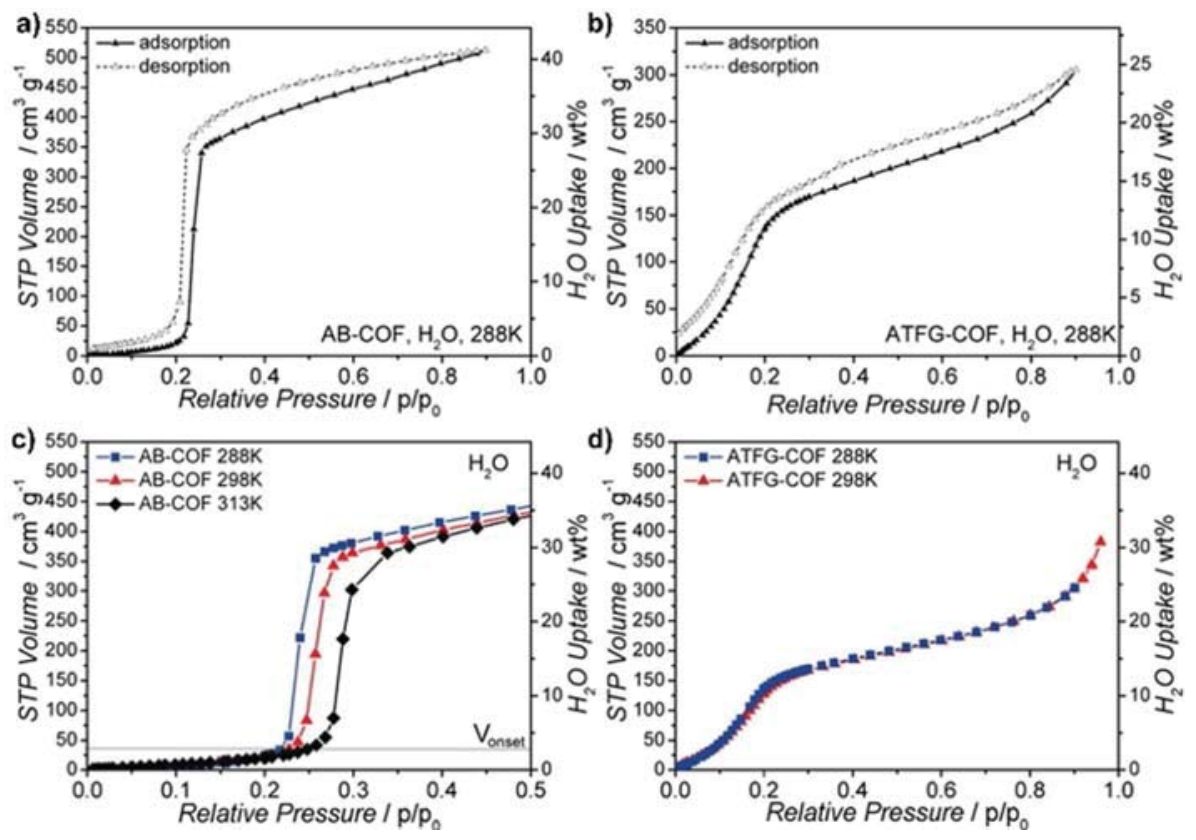

Figure 7. Water adsorption isotherms for (a) AB-COF and (b) ATFG-COF. Isotherms of (c) AB-COF and (d) ATFG-COF at different temperatures. Reprinted from Ref. [47].

S-shaped profiles. In general, the amount of adsorbed water is proportional to the pore volume, however, ATFG-COF having a higher pore volume than AB-COF showed lower water uptake. This result might originate from the "ultramicroporous" nature of ATFG-COF with a pore size of less than $0.7 \mathrm{~nm}$ as water molecules are less likely to be adsorbed in these pores. It is, however, noteworthy to mention that the pore wall of ATFG-COF is more hydrophilic owing to the presence of polar functional groups such as nitrogen or oxygen and thus the adsorption amount increases rapidly at a low relative pressure $\left(P / P_{0}=0.2\right)$.

Unlike porous carbons, a triazine-based COF with hydrophobic pore walls, trzn-COF, was shown to hardly adsorb any water. $^{[48]}$ The trzn-COF exhibited a specific surface area of $408.5 \mathrm{~m}^{2} \mathrm{~g}^{-1}$ and a pore volume of $0.21 \mathrm{~cm}^{3} \mathrm{~g}^{-1}$. The water uptake capacity was found to be only $4 \mathrm{wt} \%\left(2 \mathrm{mmolg}^{-1}\right)$. The hydrophobicity of trzn-COF led to very weak interactions with water molecules. These results clearly demonstrate that the hydrophilic/hydrophobic nature of the pore walls greatly affects the water uptake capacity and serves as a critical guideline for the development of POPs to be used as water adsorbents.

Banerjee and co-workers reported a comprehensive study on the pore wall modification of imine-linked COFs by using 12 different organic linkers. ${ }^{[49]}$ Ten COF structures were synthesized along with C2 (amine) and C3 (aldehyde) combination resulting in hexagonal structures (named as $\mathrm{H}$-series), and the other two structures were C2 (amine) with tetragonal C4 (amine-functionalized porphyrin) structure (T-series). The amine-containing monomers were functionalized with $-\mathrm{CH}_{3}$, $-\mathrm{F},-\mathrm{NO}_{2},-\mathrm{OH},-\mathrm{N}=\mathrm{N}-$ groups and the trend of water uptake capacity was correlated to the nature of the pore walls. First, the functionalization of COFs with hydrophobic groups such as $-\mathrm{F},-\mathrm{NO}_{2},-\mathrm{CH}_{3}$ led to lower water vapor adsorption capacity (Figure 8). As expected, the highest adsorption capacity was obtained from hydrophilic functional groups, DhaTab $(-\mathrm{OH}$ group, $57 \mathrm{wt} \%)$ followed by TpPa-1 (-H group, $44 \mathrm{wt} \%)$ and Tp-azo (azo-linked, $41 \mathrm{wt} \%$ ). TpPa-1 showed an abrupt increase in the water uptake at a low relative pressure range $\left(\approx P / P_{0}=0.3\right)$.

Notably, the water uptake performance of TpPa- 1 was superior to those of other carbon and MOF materials. In addition, 2,5-DhaTab with hydrophilic functional groups also showed a very high water uptake capacity of $17 \mathrm{wt} \%$. 2,3-DhaTph and 2,5-DhaTph (T-series) showed very little effect on water uptake owing to the hydrophobic nature of porphyrin units in their backbone. The water adsorption/desorption cycle performances were investigated for the three COFs-namely, TpPa-1, TpPa-2, and Tp-Azo. These polymers showed excellent singlecomponent water uptake isotherms in terms of adsorption capacity and working capacities. Over five cycles, they all showed stable adsorption/desorption performances and sustained PXRD patterns, thus demonstrating the stability of the frameworks. Although these COFs were synthesized by using glacial acetic acid as a catalyst, later on, the same group reported a new synthetic strategy by using $p$-toluenesulfonic acid (PTSA$\left.\mathrm{H}_{2} \mathrm{O}\right)^{[50]}$ as a catalyst, which improved the scalability and processability as well as morphology control over the final polymer using a suitable mold. For example, membrane, hollow tube, or a cylindrical shape could be obtained without using any binder or a crosslinking agent. More interestingly, the resulting polymers were found to be shape-persistent and did not lose their BET surface areas. Notably, the BET surface areas of the COFs synthesized by using PTSA- $\mathrm{H}_{2} \mathrm{O}$ as a catalyst were found to be two to three times higher than the ones obtained by using acetic acid. These improved surface areas led to drastically improved water vapor uptake capacities. Accordingly, the water uptake capacities of $\mathrm{TpPa}-1$ increased from 44 to 

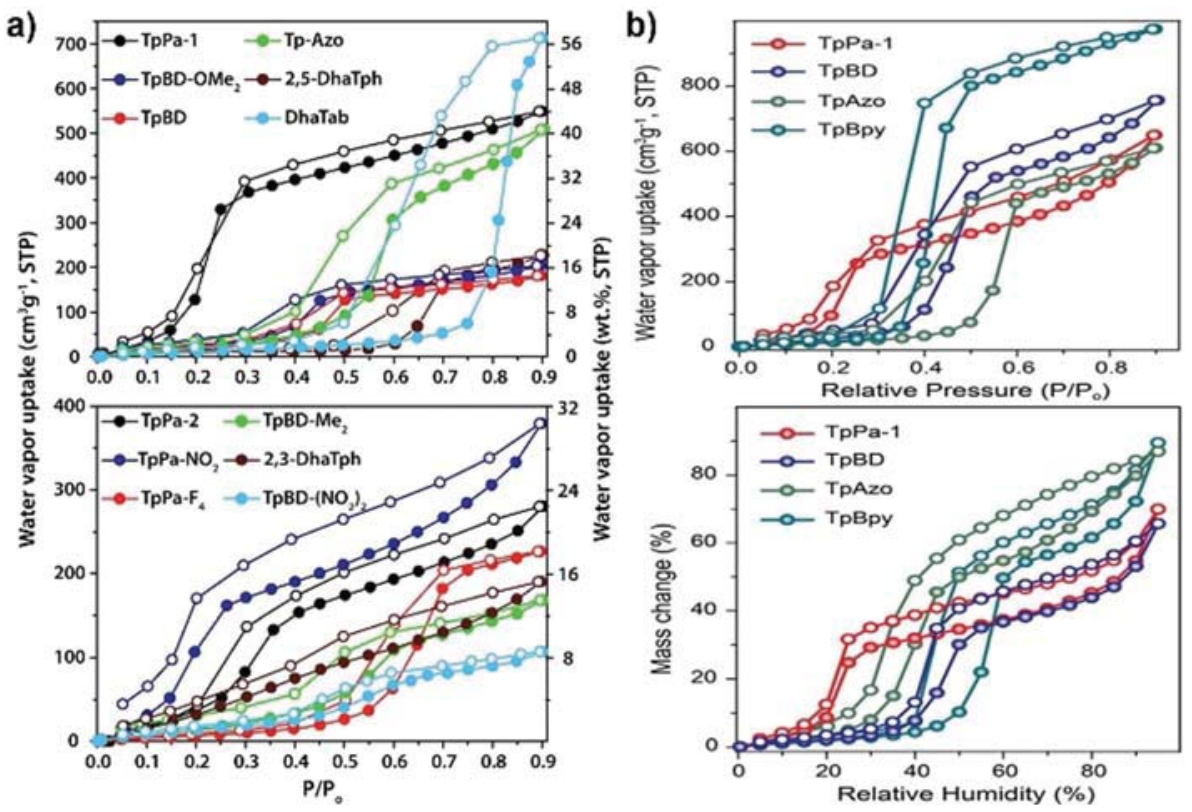

Figure 8. (a) Water sorption profiles of COFs synthesized by using acetic acid as a catalyst. (b) Water uptake isotherms of COFs obtained by using PTSA- $\mathrm{H}_{2} \mathrm{O}$ as a catalyst. Reprinted from Refs. [49] and [50], respectively.

52 wt \%, Tp-Azo from 41 to 49 wt \%, and TpBD from 15 to $61 \mathrm{wt} \%$. Furthermore, TpBpy containing bipyridine linkages exhibited a water vapor uptake capacity of 78 wt \%. Cycling performances of TpPa-1 and TpBD in a cylindrical shape were also performed for up to four cycles, which showed stable cycling without any capacity loss.

\section{Covalent triazine frameworks (CTFs)}

Covalent triazine frameworks (CTFs) are a subclass of porous organic polymers. CTFs have been applied to a variety of applications owing to their high nitrogen content, high surface area, stable structural properties, and porous structure. The first reported CTF, by Antonietti and co-workers, was synthesized under ionothermal reaction conditions by using 1,4-dicyanobenzene and $\mathrm{ZnCl}_{2}$ catalyst through the trimerization of cyano groups $(-\mathrm{CN}) .^{[51]}$ More recently, new synthetic strategies have been introduced to eliminate $\mathrm{ZnCl}_{2}$ as a catalyst owing to the difficulty of removing residual metals from micropores; these methods include strong acid, ${ }^{[52]}$ sulfur, ${ }^{[53]} \mathrm{P}_{2} \mathrm{O}_{5},{ }^{[54]}$ polycondensation reactions, ${ }^{[55]}$ or monomer tuning. ${ }^{[56]}$ Another advantage of CTFs is their structural diversity through molecularlevel design of monomers, enabling control over surface area, pore size, as well as hydrophobicity and hydrophilicity. CTFs can be obtained in both crystalline and amorphous forms depending on the reaction conditions.

In this review, we classify any porous organic polymer containing triazine units as CTF and discuss the water uptake performance of both crystalline and amorphous CTFs together in this section. Cyanate resins exhibit good thermal stability, permittivity, and mechanical properties, but they are known for their low moisture adsorption characteristics. Wang et al. ${ }^{[57]}$ transformed cyanate resins into triazine-containing polymers through thermal cyclotrimerization reactions. Each of the nitrile functionalized monomers-namely, tetrakis(4-cyanatophenyl) silane, tetrakis(4-cyanatobiphenyl) silane, and tris(4-cyanatobiphenyl) amine-was subjected to thermal cyclotrimerization by using nonylphenol as a catalyst to obtain crosslinked cyanate resin polymers (CE-1, CE-2, CE-3). The resin series (CE-1, CE-2, and (E-3) showed specific surface areas of 960,588 , and $540 \mathrm{~m}^{2} \mathrm{~g}^{-1}$, and pore volumes of $0.97,0.47$, and $0.43 \mathrm{~cm}^{3} \mathrm{~g}^{-1}$, respectively. CE-2 and CE-3 exhibited almost linear isotherms, an indication of the weak noncovalent interactions between water molecules and CE-2 and CE-3, thus pointing to the hydrophobic nature of the pore wall. The order of maximum water vapor uptake capacities at $P / P_{0}=0.9$ followed the pore volume order, CE-1 $>$ CE-2 $>$ CE-3. In addition, CE-1 is considered to be more hydrophilic compared with both $\mathrm{CE}-2$ and $\mathrm{CE}-$ 3 owing to its higher heteroatom $(\mathrm{N}, \mathrm{O})$ content.

The first attempt to use CTFs for water adsorption was reported by Lotsch's group. ${ }^{[58]}$ They tested various CTFs for water adsorption. The CTFs were obtained by using 1,4-dicyanobenzene (CTF-1), pyrimidine-2,5-dicarbonitrile (pym-CTF), 2,6-dimethylpyridine-3,5-dicarbonitrile (lut-CTF), and 2,2-bipyridine (bipy-CTF) in the presence of $\mathrm{ZnCl}_{2}$ under ionothermal conditions. The reaction temperature was varied from 300 to $600^{\circ} \mathrm{C}$. Although the low reaction temperatures $\left(300-400^{\circ} \mathrm{C}\right)$ led to the formation of crystalline CTFs, higher reaction temperatures $\left(400-600^{\circ} \mathrm{C}\right)$ led to partially carbonized, amorphous CTFs with significantly increased surface areas and porosity. Both bipyCTF500 and pym-CTF500 showed excellent performance in $\mathrm{CO}_{2}$ uptake capacity and selectivity. These CTFs were also evaluated as water vapor adsorbents (Figure 9). Although bipyCTF500 showed a gradual increase in water uptake at low pressure, the profile of pym-CTF500 steeply increased at low pressure, which indicates its higher hydrophilicity. Water 
a)

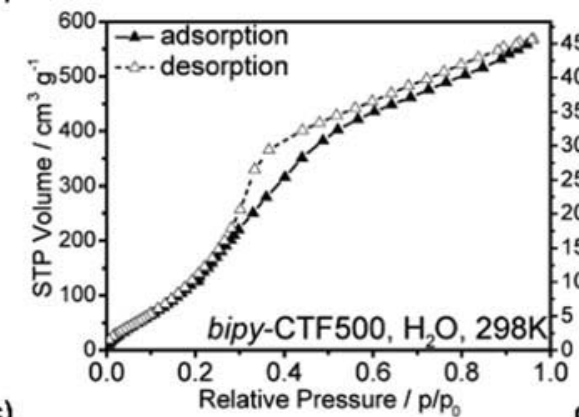

c)

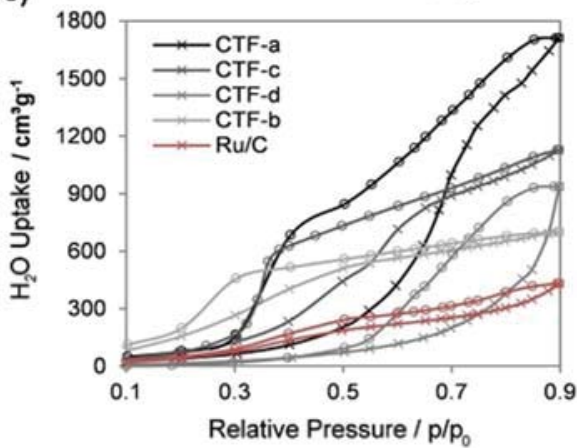

b)

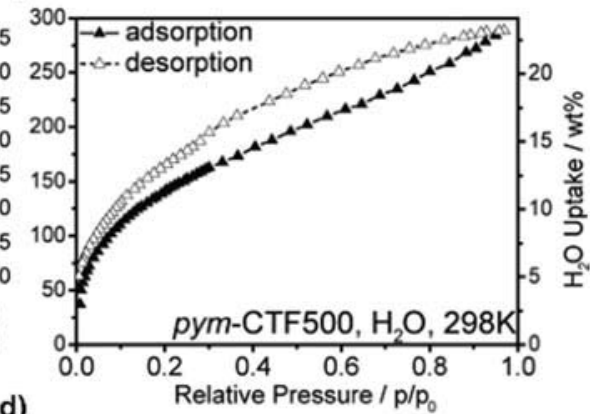

d)

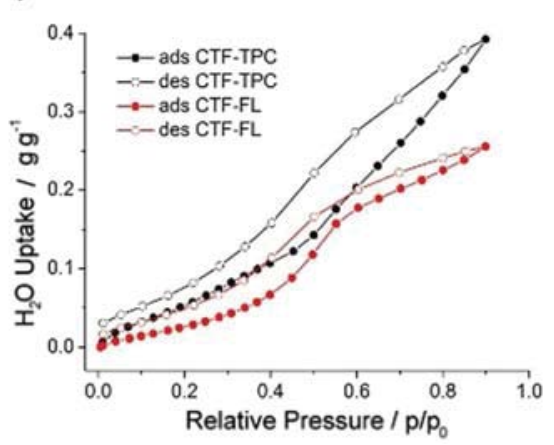

Figure 9. Water vapor adsorption/desorption isotherms of covalent triazine frameworks, (a) bipy-CTF-500, (b) pym-CTF-500, (c) CTF-a to CTF-d, and (d) CTFTPC/FL (closed symbols, adsorption; open symbols, desorption). Reprinted with permission from Refs. [58], [59], and [60], respectively.

uptake capacities of 45 and $22 \mathrm{wt} \%$ were observed at $P / P_{0}=$ 0.9 for bipy-CTF500 and pym-CTF500, respectively. Around the same time, Palkovits and co-workers used 1,3-dicyanobenzene (1,3-DCB), 2,6-pyridinedicarbonitrile (2,6-DCP), 1,4-DCB, and 4,4biphenyldicarbonitrile monomers to synthesize CTF-a, CTF-b, CTF-c, and CTF-d, respectively. ${ }^{[59]}$ Although the purpose of this study was to utilize the CTF backbone as a template for ruthenium catalysts in the oxidation of 5-hydroxymethylfurfural, the authors also carried out water adsorption experiments (Figure $9 \mathrm{c}$ ) to probe the hydrophilicity of the CTF template. CTF-a to $-d$ showed good affinity towards water vapor along with high water uptake capacities compared with the control sample, Ru/C. The highest vapor adsorption capacity was observed from CTF-a owing to the fact that it has the highest pore volume among all the CTFs tested. One way to quantify the hydrophilicity is the degree of pore filling (DPF) value, which is the ratio of total pore volume to water adsorption capacity at $P / P_{0}=0.9$. Compared with other CTFs, CTF-b showed the highest DPF value (87.5) by virtue of its high nitrogen content, whereas CTF-d with high carbon content showed only 28.5, which indicates its hydrophobicity. This result is also further confirmed by comparing the water uptake capacities at low relative pressures. Except for CTF-d, all the CTFs showed high water vapor uptakes below $P / P_{0}=0.3$, at which point the hydrophilicity of the framework becomes a very important parameter.

As mentioned above, although most of the CTFs are synthesized through the trimerization reaction using various catalysts, there are also reports on the synthesis of CTFs by FriedelCrafts reaction with cyanuric chloride, $\mathrm{AlCl}_{3}$, and $\mathrm{FeCl}_{3}$ as catalysts to reduce the synthesis temperature and avoid functional group limitations (cyano group). Janiak and co-workers synthesized CTF-TPC and CTF-FL by using triptycene (TPC) and fluorenone (FL) as monomers, respectively, which are widely used as building blocks for the preparation of POPs. ${ }^{[60]}$ Both polymers were found to be completely amorphous, which is common for kinetically controlled polymerization reactions. The surface areas of CTF-TPC and CTF-FL were found to be 1668 and $773 \mathrm{~m}^{2} \mathrm{~g}^{-1}$ with total pore volumes of 0.93 and $0.39 \mathrm{~cm}^{3} \mathrm{~g}^{-1}$, respectively. Abnormally high oxygen ratios were observed for both polymers in the elemental analysis, which prompted the authors to hypothesize that the materials are hygroscopic. To demonstrate this, the Karl-Fischer titration (KFT) method and general vapor sorption isotherms were used. KFT analysis showed that the degassed polymer can adsorb approximately 10-13 wt \% water vapor from ambient air. In contrast, vapor adsorption isotherms indicate that CTFTPC and CTF-FL can adsorb up to $34 \mathrm{wt} \%$ and $21 \mathrm{wt} \%$ of water vapor at a relative pressure of 0.9 , respectively.

Later, Janiak and co-workers employed a mixed-linker approach for the synthesis of CTFs through conventional $\mathrm{ZnCl}_{2}$ catalysis. ${ }^{[61]}$ The mixed-linker approach is a widely used method to prepare COFs or POPs and to form pores with different sizes depending on the length of the linker. As shown in Figure 10, nine different CTFs were synthesized with the combination of three different adamantine cores $\left(\mathrm{Ad}_{2}-\mathrm{Ad}_{4}\right)$ and cyano linkers $\left(L_{1}-L_{3}\right) .^{[61 a]}$ In a separate study, the authors also used tetraphenylethylene as the main core and reacted it with four different cyano linkers (M1 to M4) in the presence of $\mathrm{ZnCl}_{2}$, forming $\mathrm{MM}^{\prime}-\mathrm{CTF}$ polymers. ${ }^{[61 \mathrm{~b}]}$ As the synthesis and analysis methods are similar except the main core unit, we will discuss these results together. As listed in Table 1, all the CTFs 

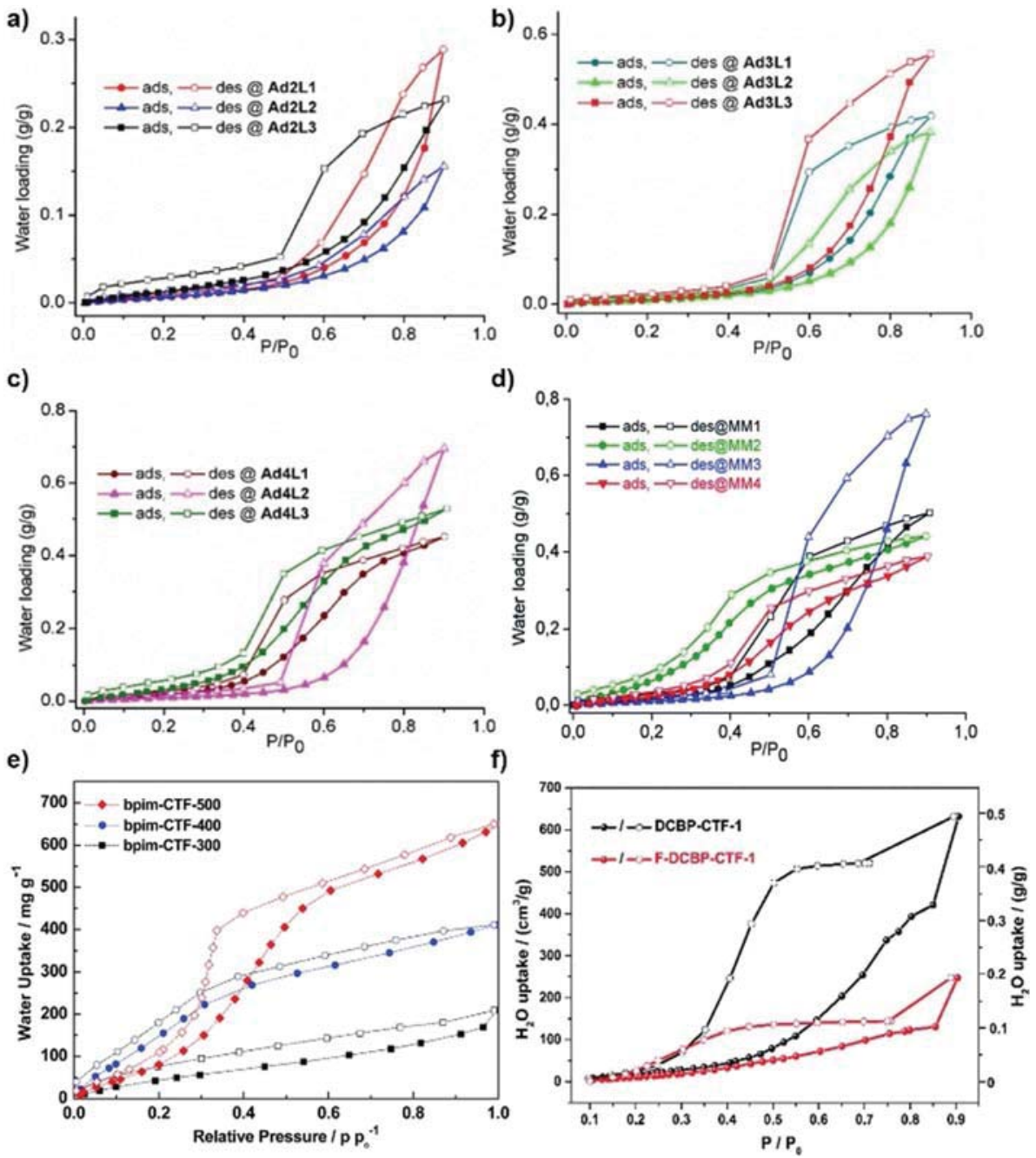

Figure 10. Adsorption isotherms (closed symbols) and desorption isotherms (open symbols) of water vapor for (a) Ad2 series, (b) Ad3 series, (c) Ad4 series, (d) MM series, (e) bpim-CTF series, and (f) F-DCBP-CTF. Reprinted with the permission from Refs. [61], [63], and [64].

based on this two-linker approach showed excellent surface areas and pore volumes. For example, $\mathrm{Ad}_{4} \mathrm{~L}_{2}-\mathrm{CTF}$ showed the surface area and pore volume values of $1885 \mathrm{~m}^{2} \mathrm{~g}^{-1}$ and $1.52 \mathrm{~cm}^{3} \mathrm{~g}^{-1}$, respectively, whereas, in the MM series, MM3 (400) showed surface area and pore volume values of $1884 \mathrm{~m}^{2} \mathrm{~g}^{-1}$ and $1.52 \mathrm{~cm}^{3} \mathrm{~g}^{-1}$, respectively. Polymers synthesized above $400^{\circ} \mathrm{C}$ were excluded owing to partial carbonization. The water adsorption isotherm of each polymer is depicted in Figure $10 \mathrm{a}-\mathrm{c}$. All the Ad and MM series showed drastically increased water uptake values at high relative pressures compared with lower relative pressures mainly owing to their hydrophobicity. Hence, the water adsorption occurred primarily through pore condensation. Among them, the pore wall of MM2 in the MM series, incorporating tetrafluorophthalonitrile as a linker, is expected to be highly hydrophobic owing to the presence of fluorine atoms. However, MM2 showed a much higher adsorption capacity at a lower relative pressure compared with other polymers as shown in Figure $10 \mathrm{~d}$. The authors explained this phenomenon by the capillary condensation effect within the micropores of MM2 as well as the hydrogen-bonding interactions. Although it is common to explain the difference in adsorption at low relative pressures simply by the hydrophobicity or hydrophilicity of the pores, it is rather difficult to exclude the effects originating from pore volume, pore size distribution, or other physical properties of the POPs. The above-mentioned experiments demonstrate that POPs exhibit a certain amount of water vapor adsorption at low relative pressures from ambient air. Coskun and co-workers ${ }^{[62]}$ also reported a similar behavior for the charged CTFs, for which TGA revealed significant mass loss at elevated temperatures $\left(<150^{\circ} \mathrm{C}\right)$. The hydrophilic nature of cationic CTFs were also shown by Yoon and co-workers for CTFs incorporating imidazolium ions, bpim-CTF. ${ }^{[63]}$ The hygroscopic nature of bpim-CTF was verified from TGA with about $13 \mathrm{wt} \%$ weight loss in the temperature range $100-120^{\circ} \mathrm{C}$, which could indicate the uptake of atmospheric moisture along with residual solvents. Notably, the water adsorption/desorption isotherms illustrate significant increase in water uptake with increasing polymerization temperature. This result can be explained by the increasing pore volume (N/D, 0.34, $0.75 \mathrm{~cm}^{3} \mathrm{~g}^{-1}$ for bpim-CTF300, CTF-400, CTF-500, respectively) with rising reaction temperature. It is, however, important to note that at low relative 
pressures, below 0.3, bpim-CTF-400 showed the highest water uptake capacity followed by bpim-CTF-500 (Figure 10e). This result can be explained by the significant loss of nitrogen atoms at $500^{\circ} \mathrm{C}$ and the consequent decrease in hydrophilicity.

Very recently, Van Der Voort and co-workers synthesized fluorine-substituted CTF, F-DCBP, under ionothermal reaction conditions by reacting 2,2,3,3,5,5,6,6-octafluoro-4,4-biphenyldicarbonitrile (F-DCBP) in the presence of $\mathrm{ZnCl}_{2}$ catalyst. ${ }^{[64]}$ Fluorine atoms are known to undergo partial dehydrofluorination and vaporize in the form of carbon-fluorine gas at elevated temperatures. DCBP-CTF synthesized from 4,4-biphenyldicarbonitrile (without any fluorine atoms) was used as a control sample. In good agreement with the previously reported CTFs, the specific surface area of F-DCBP was found to largely depend on the $\mathrm{ZnCl}_{2}$ ratio and the reaction temperature. FDCBP-CTF-1 with 5 equivalents of $\mathrm{ZnCl}_{2}$ exhibited a surface area of $1574 \mathrm{~m}^{2} \mathrm{~g}^{-1}$, whereas F-DCBP-CTF-2 with 10 equivalents showed a surface area of $1126 \mathrm{~m}^{2} \mathrm{~g}^{-1}$. However, an opposite trend was observed in the pore volumes. F-DCBP-CTF-2 showed a slightly higher pore volume of $1.56 \mathrm{~cm}^{3} \mathrm{~g}^{-1} \mathrm{com}-$ pared with F-DCBP-CTF-1 $\left(1.50 \mathrm{~cm}^{3} \mathrm{~g}^{-1}\right)$. The control polymers, DCBP-CTF-1 and DCBP-CTF-2, exhibited surface areas of 2437 and $2036 \mathrm{~m}^{2} \mathrm{~g}^{-1}$ along with pore volumes of 1.48 and $2.26 \mathrm{~cm}^{3} \mathrm{~g}^{-1}$, respectively. Elemental analysis revealed substantially lower fluorine contents for both F-DCBP-CTF-1 (4.2 wt\%) and F-DCBP-CTF-2 (3.13 wt \%) compared with the theoretical value of $43 \mathrm{wt} \%$. The authors performed water vapor sorption measurements to investigate the effect of such a small amount of fluorine on the pore walls. The authors were able to show (Figure $10 \mathrm{f}$ ) that the slightly hydrophobic F-DCBP-CTF-1 showed much lower water vapor uptake capacities compared with DCBP-CTF-1 in the entire pressure range. Considering the similar pore volume of these polymers $\left(1.48 \mathrm{vs} .1 .50 \mathrm{~cm}^{3} \mathrm{~g}^{-1}\right)$ and mesoporosity of F-DCBP-CTF-1, a large difference in the adsorption capacity indicates that the $\mathrm{C}-\mathrm{F}$ bond impeded the adsorption of water molecules in the micropores.

\section{Amorphous porous organic polymers as desiccants}

POPs have attracted much attention in recent years owing to their controllable surface area, permanent porosity, wide range of available synthetic routes and building blocks and, most importantly, high moisture and thermal stability. These polymers were found to be mostly amorphous owing to the kinetically controlled reaction conditions. POPs have been extensively studied in the gas capture and separation applications targeting $\mathrm{CO}_{2}, \mathrm{H}_{2}$, toxic gases, and, recently, water capture. However, it should be mentioned that the application of POPs in the context of water capture is still in its infancy, and further research efforts are expected in the coming years considering the importance of this particular research area. In the following section, we summarized POPs tested for water sorption and the polymers were categorized based on their hydrophobic/ hydrophilic nature. More specifically, hydrophobic adsorbents include polymers that primarily focus on the adsorption of gases against moisture, thus showing little to no affinity to- wards water molecules, whereas hydrophilic POPs are the ones reported mainly for water sorption applications.

\section{Water unfavorable POPs}

\section{Single-component water vapor sorption}

Han and co-workers synthesized a series of porous conjugated polycarbazoles $^{[65]}$ (CPOP-8, CPOP-9, CPOP-10) by varying the number of phenyl rings in the monomers. Among all the CPOPs, CPOP-9 showed the highest surface area of $2440 \mathrm{~m}^{2} \mathrm{~g}^{-1}$ and exhibited a predominantly mesoporous structure with pore size in range $2.5-5.0 \mathrm{~nm}$. Despite of its hydrophobicity, CPOP-9 showed (Figure 11a) high moisture uptake up to $64.6 \mathrm{wt} \%$ at $P / P_{0}=0.99$, consistent with its high pore volume $\left(2.04 \mathrm{~cm}^{3} \mathrm{~g}^{-1}\right)$. The pore volumes were found to be lower for CPOP-8 $\left(1.71 \mathrm{~cm}^{3} \mathrm{~g}^{-1}\right)$ and CPOP-10 $\left(0.76 \mathrm{~cm}^{3} \mathrm{~g}^{-1}\right)$, which in turn, resulted in much lower water uptake capacities of 16.7 and $13.6 \mathrm{wt} \%$, respectively. The water adsorption isotherms of CPOP-8 and 10 showed a single step adsorption at $P / P_{0}=0.7$, which could be attributed to physisorption, swelling, and capillary condensation within the pore walls of the mesopores. A wide hysteresis loop in the case of CPOP-9 points to a different mechanism, that is, adsorption/pore filling and desorption within hydrophobic materials. The water uptake in CPOP-9 is only observed at high relative pressures.

In addition, Han et al. ${ }^{[66]}$ also reported the synthesis of porous conjugated polymers (CPOP-11 and CPOP-12) incorporating porphyrin or $\mathrm{Fe}^{\prime \prime}$-porphyrin moieties for the adsorption of organic vapors such as toluene and methanol. Both CPOPs showed much higher uptake values towards toluene and methanol compared with water, as shown in Figure $11 \mathrm{~b}$ and $\mathrm{c}$. Toluene adsorption isotherms present a gradual rise in adsorption until the material reaches saturation at $96 \mathrm{wt} \%$ for CPOP11 and $119.2 \mathrm{wt} \%$ for CPOP-12. The good sorption capacity towards toluene is attributed to the high porosity, complete organic nature, and affinity to the guest molecules through $\pi-\pi$ and $\mathrm{C}-\mathrm{H} / \pi$ interactions. Moreover, CPOP-12 featuring a Fe" porphyrin complex is relatively electron deficient, thus further increasing the affinity towards relatively electron-rich toluene molecules. For methanol sorption, CPOPs also present a gradual rise, which reaches up to $73.0 \mathrm{wt} \%$ for CPOP-11 and $76.6 \mathrm{wt} \%$ for CPOP-12 at the saturated vapor pressure of methanol. With respect to the sorption of organic vapors, water vapor adsorption showed much decreased values. The water sorption of CPOP-11 presents little to no uptake until a relative pressure of 0.8 (Figure $11 \mathrm{~b}$ ), which saturates at $4.6 \mathrm{wt} \%$. The hydrophobic nature of CPOP-11 allows the extraction of methanol vapor under humid conditions. In contrast, CPOP-12 showed much higher water uptake capacity of 25.5 wt \%, which is attributed to the increased hydrophilicity owing to the presence of the Fe"-porphyrin complex. The ironporphyrin complex also showed a desorption hysteresis at $P / P_{0}$ $=0.5-1.0$ presumably owing to the interactions between water molecules and the metal centers.

Wang et al. ${ }^{[67]}$ reported the synthesis of microporous poly(Schiff base), PSN-3, in which each tetraphenyladamantane moiety is connected by aldimine functionalities through a con- 

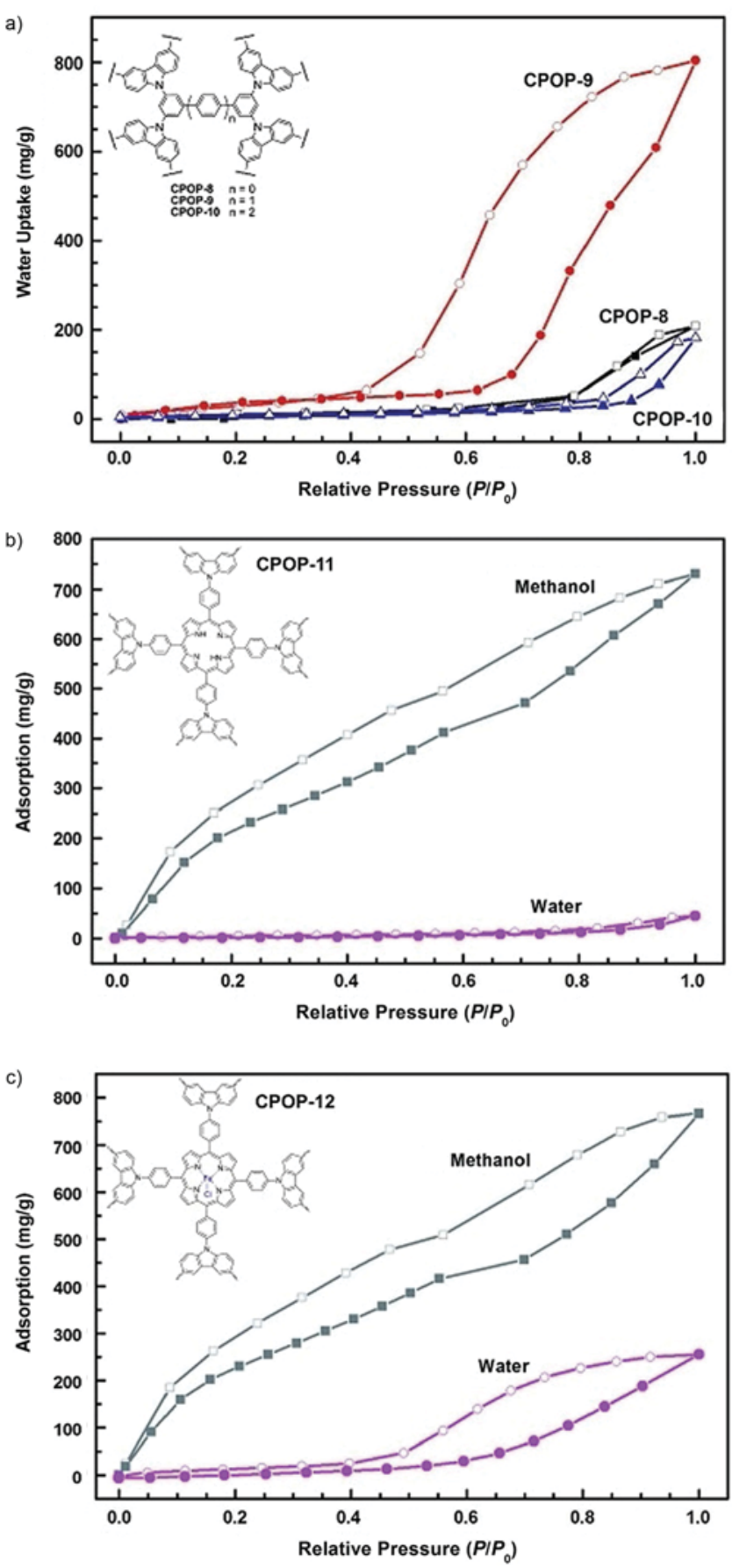

Figure 11. Adsorption (closed symbols) and desorption isotherms (open symbols) of water and methanol for (a) CPOP-8, CPOP-9, CPOP-10, (b) CPOP11, and (c) CPOP-12. Reprinted with permission from Refs. [65] and [66].

densation reaction between formyl and amino groups. The nitrogen sorption analysis of PSN-3 showed the BET surface area of $865 \mathrm{~m}^{2} \mathrm{~g}^{-1}$ with the presence of micropores centered at about $0.60 \mathrm{~nm}$ as well as mesopores in the range $2-30 \mathrm{~nm}$. Owing to its high porosity, PSN-3 presents potential for the adsorption of benzene $\left(80.5 \mathrm{wt} \%\right.$ at $\left.P / P_{0}=0.9\right)$ and cyclohexane (63.7 wt $\%$ at $P / P_{0}=0.9$ ). However, the water sorption presents a type III isotherm with a maximum uptake of only $6.4 \mathrm{wt} \%$. Wang et al. ${ }^{[68]}$ developed microporous polyimides that incorpo- rate tetraphenylmethane and different linkers, namely, (hexafluoroisopropylidene)diphenyl (MPI-6FA), benzophenone (MPIBPA), and biphenyl (MPI-BTA). Compared with non-fluorinated polymers, the fluorinated MPI-6FA showed a higher BET surface area $\left(781 \mathrm{~m}^{2} \mathrm{~g}^{-1}\right)$, micropore surface area $\left(473 \mathrm{~m}^{2} \mathrm{~g}^{-1}\right)$, and micropore volume $\left(0.22 \mathrm{~cm}^{3} \mathrm{~g}^{-1}\right)$. Despite its high surface area and micropore volume, the water vapor uptake capacity of MPI-6FA was found to be smaller compared with other MPIs. The water sorption isotherm of MPI-6FA is found to be type III with a water uptake capacity of only $8.5 \mathrm{wt} \%$ at a relative pressure of 0.8 . The convex-shaped isotherm implies the hydrophobicity of MPI-6FA is due to the presence of trifluoromethyl groups, which can effectively reduce the interaction between water molecules and the pore walls. The presence of hydrophobic fluorine atoms significantly alters the water uptake properties, thus clearly showing the impact of the hydrophobicity of microporous networks. Clearly, the type of functional groups is a significant factor in determining the degree of hydrophobicity within POPs. Provided that the polymers possess a similar degree of hydrophobicity, the higher pore volume leads to increased water uptake capacity.

\section{Multi-component vapor sorption}

In the flue gas mixture, water is the third major component by volumetric concentration. Owing to the presence of water, porous materials experience difficulty in selectively capturing $\mathrm{CO}_{2}$ as a result of the competitive binding, which generally results in a decreased $\mathrm{CO}_{2}$ uptake capacity as well as an inferior long-term stability. Although most of the porous materials lose their $\mathrm{CO}_{2}$ uptake capacity, amine-doped porous organic polymers showed improved affinities. For example, Hamouz et al. ${ }^{[69]}$ reported an amine-rich crosslinked porous organic polymer (KFUPM-1) and performed breakthrough measurements to separate $\mathrm{CO}_{2}$ from $\mathrm{N}_{2}$ gas. First, the long-term stability of KFUPM1 was investigated through a multicycle continuous water uptake test at $313 \mathrm{~K}$ and $\mathrm{RH}=76 \%$. Up to 20 cycles, the material retained its water uptake properties, which indicates good water stability within the given cycle range. For breakthrough experiments, the bed was packed with activated KFUPM-1 powder and subjected to a gas mixture containing $\mathrm{CO}_{2}$ and $\mathrm{N}_{2}$ $(20: 80 \mathrm{v} / \mathrm{v})$ under dry or wet $(\mathrm{RH}=91 \%)$ conditions. Under both conditions, KFUPM- 1 selectively captured $\mathrm{CO}_{2}$ whereas $\mathrm{N}_{2}$ passes through the material. The longer $\mathrm{CO}_{2}$ retention time is shown under humid conditions because KFUPM-1 adsorbs approximately $33.5 \mathrm{wt} \%$ water at $91 \% \mathrm{RH}$, which leads to stronger interactions with $\mathrm{CO}_{2}$.

Hupp et al. ${ }^{[7]}$ presented a diimide-based porous organic polymer (NU-POP-1) for the capture of toxic industrial chemicals such as octane, ammonia, $\mathrm{CNCl}$, and $\mathrm{SO}_{2}$. As adsorbed water can alter the effectiveness of the sorbent, the performance of NU-POP-1 was compared under dry and humid conditions. First, in single-component water uptake experiments, NU-POP-1 showed a gravimetric water uptake capacity of approximately $22.5 \mathrm{wt} \%$ at $\mathrm{RH}=90 \%$. In the entire humidity region, NU-POP-1 showed a continuous increase in water uptake, which was attributed to its hydrophilicity, originating 
from oxygen and nitrogen sites on the naphthalene diimide linkers. For binary micro-breakthrough experiments, the bed was filled with activated NU-POP-1 and subjected to one of chemicals such as octane, ammonia, $\mathrm{CNCl}$, and $\mathrm{SO}_{2}$ under dry or wet $(\mathrm{RH}=80 \%)$ conditions. Under dry conditions, NU-POP-1 showed high uptake capacities, whereas under humid conditions, the material yielded elongated curves owing to competitive adsorption of organic vapors and water.

\section{Water favorable POPs}

POPs are extremely stable under humid conditions, which renders them as excellent candidates for water capture applications. Hydrophilic POPs can be obtained by the incorporation of various heteroatoms (i.e., O, B, N, P, S) either as functional groups or bridging groups, which can positively contribute to the interactions with water molecules.

In 2014, Kaskel et al. ${ }^{[71]}$ reported a series of 2D porous organic polymers OCF-1, DUT-92, and DUT-93 in the order of increasing number of phenyl moieties and also their derivatives with different functionalities such as $\mathrm{NO}_{2}$ and $\mathrm{NH}_{2}$ for DUT-92 and DUT-93. Interestingly, at low relative pressures, the water uptake properties of these polymers depended mainly on the interaction between water molecules and functional groups rather than the surface area and pore volume. The nitrogen adsorption isotherm of OCF-1, DUT-92, and DUT-93 showed high pore volumes above $1.02 \mathrm{~cm}^{3} \mathrm{~g}^{-1}$ determined at a relative pressure of 0.97 . However, the water sorption isotherms showed significantly low uptake in the low-pressure region, indicating a type III isotherm. This result was attributed to the highly hydrophobic nature of the porous networks. With the increasing number of phenyl moieties, the polymers exhibited a decrease in their surface area and higher hydrophobicity. Similarly, a type III water adsorption isotherm is also observed for the polymers with nitro-functionalities accompanied by a small increase in the slope below $P / P_{0}=0.2$, pointing to a slightly polar surface owing to the nitro groups. Furthermore, the degree of pore filling increases by $30-60 \%$ from non-functionalized polymers DUT-92 and DUT-93 to nitro-functionalized DUT-92 $\left(\mathrm{NO}_{2}\right)$ and DUT-93 $\left(\mathrm{NO}_{2}\right)$. On the other hand, amine-functionalized DUTs showed water uptake starting at partial pressures below $P / P_{0}=0.1$, indicating a more polar surface created by the amine groups. The water uptake capacity achieved with DUT-92 $\left(\mathrm{NH}_{2}\right)$ was $24.5 \mathrm{wt} \%$ at $P / P_{0}=0.9$, which is much higher compared with the unfunctionalized DUT-92 with an uptake capacity of only $8.0 \mathrm{wt} \%$ at $P / P_{0}=0.9$.

Senker et al. ${ }^{[72]}$ reported the synthesis of porous imine-linked networks - namely, PIN1 and PIN2-incorporating triazine moieties by using DMSO as a solvent. Interestingly, when using DMSO as a solvent, the decomposition of DMSO at high temperatures led to the protonation of imine groups, thus forming ion pairs between $\mathrm{C}=\mathrm{NH}^{+}$anionic decomposition products of DMSO. The presence of ionic functional groups rendered PIN1 and PIN2 highly polar and hydrophilic. In addition, from IAST (ideal adsorbed solution theory) calculations, the PINs presented high selectivity towards $\mathrm{H}_{2} \mathrm{O}$ over $\mathrm{CO}_{2}$ (79.1 for PIN1 and 79.6 for PIN2) at $298 \mathrm{~K}$. In comparison, PIN1 and 2 synthesized in DMF resulted in the formation of neutral polymers, which, in turn, led to much lower water uptake capacity $(5.4 \mathrm{wt} \%$ at $\mathrm{RH}=90 \%$ ) and also low selectivity (27.4) towards $\mathrm{H}_{2} \mathrm{O}$.

Apart from imine-linked porous networks, Senker et al. ${ }^{[73]}$ also reported a series of microporous organic polyimides (Figure $12 \mathrm{a}$ ), which incorporate a range of bridging groups includ-

a)
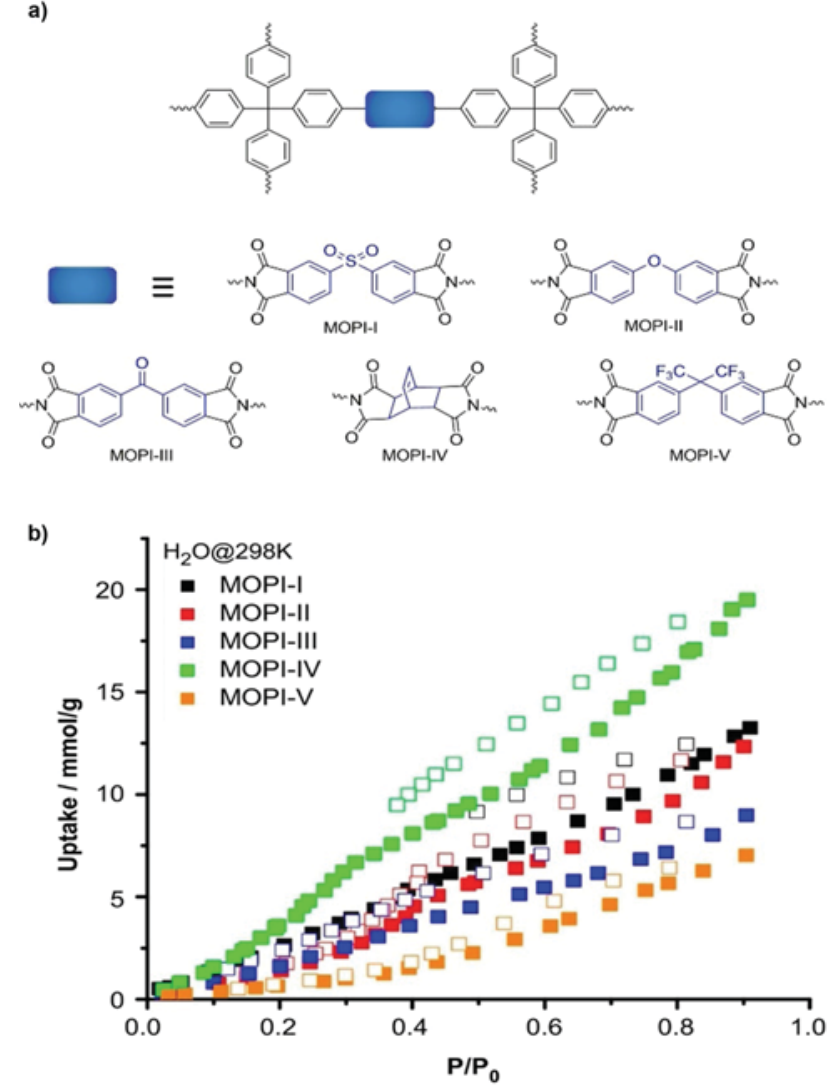

Figure 12. (a) Representation of MOPIs. (b) Adsorption (closed symbols) and desorption isotherms (open symbols) of water vapor for MOPIs. Reprinted with permission from Ref. [73].

ing diphenylsulfone (MOPI-I), diphenylether (MOPI-II), benzophenone (MOPI-III), bicycle[2,2,2]oct-7-en (MOPI-IV), and hexafluoro-2,2-diphenylpropane (MOPI-V). All of the water sorption isotherms (Figure 12b) showed a gradual rise throughout the entire relative pressure range, indicating that the sorbents contain hydrophilic sites. However, the degree of hydrophilicity differs depending on the polarity of the bridging groups, which is verified by the water sorption experiments. In agreement with the previous work by Kaskel et al., ${ }^{[71]}$ the water sorption depends more on the interaction with functional groups rather than the surface area and pore volume. MOPI-IV, incorporating the bicyclooctene moiety, showed the highest water uptake capacity of $34.4 \mathrm{wt} \%$ at $P / P_{0}=0.9$. MOPI-V with hexafluoro-functionalities presented the lowest water uptake capacity of $12.5 \mathrm{wt} \%, P / P_{0}=0.9$ while exhibiting the highest surface area. The uptake capacities at $\mathrm{RH}=90 \%$ follow the order of bicyclo[2,2,2]oct-7-en $>$ diphenylsulfone $>$ diphenylether $>$ benzophenone $>$ hexafluoro-2,2-diphenylpropane in 
agreement with the decreasing hydrophilicity of the frameworks.

In 2017, Yavuz et al. ${ }^{[74]}$ synthesized a hygroscopic POP through the polymerization reaction between cyanuric chloride and 1,4-diazabicyclo[2.2.2]octane (Figure 13a). The resulting

a)
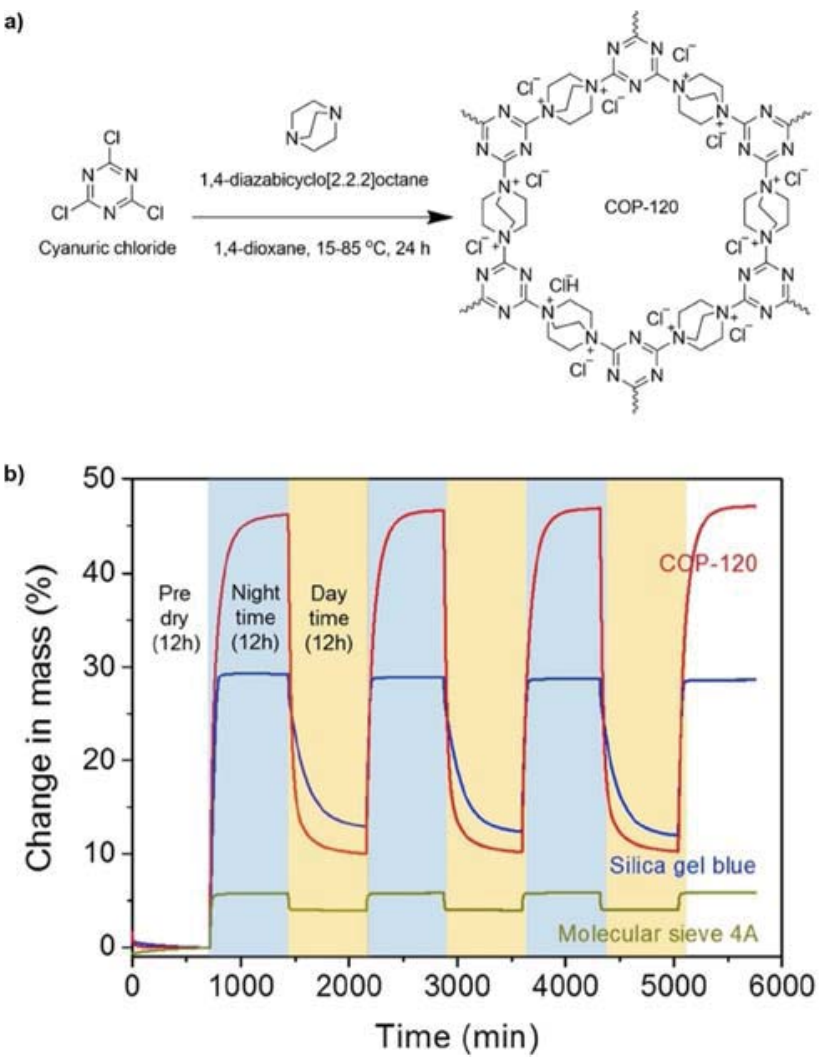

Figure 13. (a) Schematic representation of COP-120. (b) Dynamic vapor sorption cycles measured at $25^{\circ} \mathrm{C}$ for COP- 120 and commercial desiccants such as silica blue and molecular sieves $(4 \AA)$. The day and night time conditions are controlled by changing the relative humidity between $\mathrm{RH} 30 \%$ (day) and RH $80 \%$ (night). Reprinted with permission from Ref. [74].

charged POP, named COP-120, incorporates quaternary ammonium linkages. The hygroscopic properties induced by the charged centers led to a volumetric water uptake capacity as high as $44.9 \mathrm{wt} \%$ at $P / P_{0}=0.9$. In the moisture uptake cycles (Figure $13 \mathrm{~b}$ ), the activated COP-120 was subjected to a humidified gas flow with relative humidity according to day $(\mathrm{RH}=30 \%)$ and night $(\mathrm{RH}=80 \%)$ time conditions. The temperature was maintained at $25^{\circ} \mathrm{C}$ for the entire cycle and COP- 120 showed good reversibility without any performance loss.

Most recently, Byun and Coskun ${ }^{[75]}$ reported the synthesis of epoxy-functionalized porous organic polymers (ep-POPs) through a catalysis-free, one-pot Diels-Alder cycloaddition polymerization (Figure 14a). In the volumetric water uptake experiments, ep-POPs presented hydrophilic characteristics with a continuous increase in the entire pressure range. At $90 \% \mathrm{RH}$, ep-POPs showed water uptake capacities as high as $41.1 \mathrm{wt} \%$, which was attributed to their high surface area as well as efficient hydrogen-bonding interactions between epoxy moieties and water molecules. Also, the pore size of ep-POPs is slightly a)
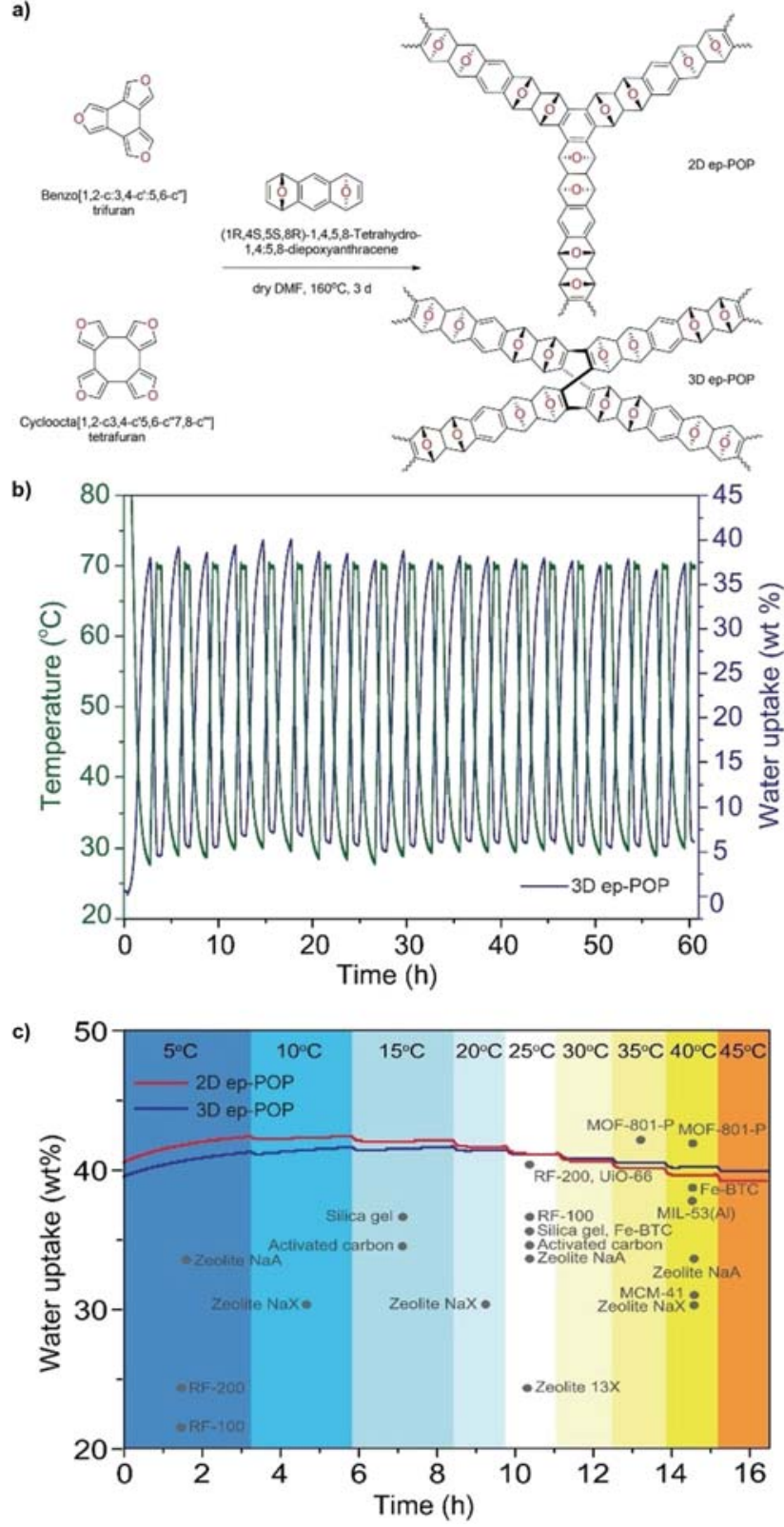

Figure 14. (a) Schematic representation of ep-POPs. (b) Dynamic vapor sorption cycles measured at constant $\mathrm{RH}=90 \%$ for $3 \mathrm{D}$ ep-POP. The temperature was varied between 30 and $70^{\circ} \mathrm{C}$ for 40 cycles for consecutive adsorption and desorption isotherms. (c) Gravimetric water sorption experiments of 2D and $3 \mathrm{D}$ ep-POPs in the temperature range $5-45^{\circ} \mathrm{C}$. Reprinted with permission from Ref. [75].

larger than the kinetic diameter of a water molecule $(2.6 \AA)$, thus allowing easy diffusion of water molecules within the pores in the entire region of the relative humidity. By measuring water sorption isotherms at 298 and $313 \mathrm{~K}$, isosteric heats of adsorption $\left(Q_{\mathrm{st}}\right)$ for water adsorption were calculated for $2 \mathrm{D}$ $\left(48.1 \mathrm{~kJ} \mathrm{~mol}^{-1}\right)$ and 3D ep-POP $\left(59.6 \mathrm{~kJ} \mathrm{~mol}^{-1}\right)$. These $Q_{\text {st }}$ values enabled low regeneration temperatures for $2 \mathrm{D}$ ep-POP $\left(55^{\circ} \mathrm{C}\right)$ and $3 \mathrm{D}$ ep-POP $\left(100^{\circ} \mathrm{C}\right)$. The cycling experiments are illustrated in Figure $14 \mathrm{~b}$ for 3D ep-POP. 3D ep-POP is exposed to $90 \% \mathrm{RH}$ when using $\mathrm{N}_{2}$ as a carrier gas. The temperature was varied between 40 and $70^{\circ} \mathrm{C}$ for 40 cycles and 3D ep-POP showed ex- 
ceptional water stability with no loss in water uptake capacity. Additionally, as described in the earlier section for potential applications, each water sorption application has a desired temperature and humidity range. Therefore, for practical applications, the desiccants should retain their high uptake capacity under a broad range of temperatures. In this regard, the authors also presented gravimetric water sorption isotherms at various temperatures, ranging from 5 to $45^{\circ} \mathrm{C}$ at constant $90 \%$ $\mathrm{RH}$ (Figure 14c). Both 2D and 3D ep-POPs showed almost constant uptake in the entire temperature range with working capacities of $39.2-42.4 \mathrm{wt} \%$ and $39.9-41.7 \mathrm{wt} \%$ for $2 \mathrm{D}$ ep-POP and 3D ep-POP, respectively. The authors emphasized three inherent properties of ep-POPs that can allow exceptional water capture properties: (i) the ideal pore size of ep-POPs allows easy diffusion of water molecules within the pores in the entire relative humidity range; (ii) epoxy functionality is the ideal binding site for water molecules through hydrogen bonding, which provides good reversibility and low regeneration temperatures; (iii) the high content of binding sites allows almost constant uptake in the broad temperature range. Notably, ep-POPs can be applied regardless of geographical region in which they are applied owing to their good cycling performance over a wide temperature range along with a low activation temperature.

\section{Summary and Outlook}

Water vapor adsorption within the cavities of nanoporous materials is manifested by its sensitivity and selectivity towards the surface functionalities, porous structure, structural morphology, hydrophilicity, and hydrophobicity. In this review, the current discoveries pertaining to nanoporous adsorbent materials for water vapor adsorption and the mechanisms associated with the sorption profile along with emphasis on the structural modification strategies are presented. The access of water molecules into the nanosized pores within the nanoporous materials incorporating various functional groups opened up a new class of desiccant materials, which combine unique capabilities emergent from the combination of porosity with the hydrophilic functional groups. Accordingly, we highlighted some of the recent progress in understanding the structural properties of nanoporous materials such as zeolites, nanoporous carbons, crystalline and amorphous porous organic polymers (Table 1), which dictate and ultimately lead to their intrinsic desiccant properties. The water sorption ability of nanoporous materials is mainly related to their hydrophilicity, which primarily originates from heteroatoms such as, boron, nitrogen, oxygen, metals, and charged atoms present in their backbone. Metal-organic frameworks (MOFs) and MOF-based hybrid materials certainly show high water adsorption capacities along with low regeneration temperatures, however, the development of metal-free porous organic polymers with high surface areas and functional elements are highly desirable for water adsorption because of environmental sustainability and to avoid any metal contamination as well as to realize easy regeneration of adsorbents. The hydrophilicity/hydrophobicity, molecular dimensions, connectivity, and dynamic interaction of porous organic polymers with water molecules can be regulated by the judicious selection of the building blocks. A variety of porous organic polymers POPs with various heteroatoms have already been reported, and their investigation in the context of water vapor capture would certainly allow us to establish an in-depth understanding of the potential of these materials.

The water adsorption ability of porous organic polymers is related to the presence of high microporosity, high pore volume, amount/nature of functional groups, and their distinctive interactions with the water molecules. Incorporation of polar organic functionalities or ions within porous organic polymers without compromising their microporous structure and high surface areas is proven to be an efficient strategy to enhance the water adsorption capacity and selectivity. The degree of hydrophilicity in porous organic polymers can be varied by introducing nitrogen and oxygen functionalities including triazine, amine, imine, hydroxy, and epoxy functional groups. The water vapor sorption on POPs heavily depends on the interaction of water molecules with the functional groups rather than the surface area and pore volume. The porous organic polymers can be also processed into various shapes/ forms for their integration into water capture/separation systems such as polymer membranes and adsorbent particles in composite membranes. The advantages of porous organic polymers for water vapor adsorption in comparison to the other adsorbents can be listed as their simple preparation methods, metal-free nature, easy incorporation of hydrophilic functional groups, high water stability, low regeneration temperatures, light weight, and the high microporosity with tunable textural/structural properties. Although considerable advances have been made for water adsorption by using porous organic polymers, the research is still in its infancy and further research efforts need to develop new catalysts-free polymerization strategies, which can allow simultaneous incorporation of high amounts of heteroatoms as well as high surface areas. In addition, any polymerization reaction should be scalable, and low-cost. The design of micron-sized porous organic polymer beads or polymer thin films/membranes, which can reversibly adsorb a very large amount of water within a narrow relative humidity window with long-term stability, adsorption kinetics, heat transferability, and shaping/processing are important aspects, which still need to be investigated in-depth. Moreover, considering the competitive binding between $\mathrm{CO}_{2}$ and $\mathrm{H}_{2} \mathrm{O}$ molecules for the flue gas separation, understanding the water uptake behavior of porous organic polymers could enable simultaneous realization of hydrophobicity and $\mathrm{CO}_{2}-$ philicity.

It is clear that the future of porous organic polymers in this emerging area is bright and their unique structural features render them as highly promising candidates for desiccation, ranging from atmospheric water capture to various manufacturing processes. 


\section{Acknowledgments}

The authors acknowledge the support from the Basic Science Research Program through the National Research Foundation of Korea (NRF) funded by the Ministry of Education (2017R1A6A3A01005029).

\section{Conflict of interest}

The authors declare no conflict of interest.

Keywords: carbon dioxide separation - organic desiccants porous organic polymers $\cdot$ surface area $\cdot$ water vapor capture

[1] M. S. Shafeeyan, W. M. A. W. Daud, A. Houshmand, A. Shamiri, J. Anal. Appl. Pyrolysis 2010, 89, 143-151.

[2] B. M. Weckhuysen, J. Yu, Chem. Soc. Rev. 2015, 44, 7022-7024.

[3] a) S. S. Chui, S. M.-F. Lo, J. P. H. Charmant, A. G. Orpen, I. D. Williams, Science 1999, 283, 1148-1150; b) H. Li, M. Eddaoudi, M. O'Keeffe, O. M. Yaghi, Nature 1999, 402, 276-279.

[4] A. P. Cote, A. I. Benin, N. W. Ockwig, M. O'Keeffe, A. J. Matzger, O. M. Yaghi, Science 2005, 310, 1166-1170.

[5] S. Das, P. Heasman, T. Ben, S. Qiu, Chem. Rev. 2017, 117, 1515-1563.

[6] R. Shenhar, T. B. Norsten, V. M. Rotello, Adv. Mater. 2005, 17, 657-669.

[7] P. Li, J. A. Modica, A. J. Howarth, E. L. Vargas, P. Z. Moghadam, R. Q. Snurr, M. Mrksich, J. T. Hupp, O. K. Farha, Chem 2016, 1, 154-169.

[8] M. O. Adebajo, R. L. Frost, J. T. Kloprogge, O. Carmody, S. Kokot, J. Porous Mater. 2003, 10, 159-170.

[9] K. S. W. Sing, D. H. Everett, R. A. W. Haul, L. Moscou, R. A. Pierotti, J. Rouquerol, T. Siemieniewska, Pure Appl. Chem. 1985, 57, 603-619.

[10] A. M. Ribeiro, T. P. Sauer, C. A. Grande, R. F. P. M. Moreira, J. M. Loureiro, A. E. Rodrigues, Ind. Eng. Chem. Res. 2008, 47, 7019-7026.

[11] D. Ferreira, R. Magalhaes, P. Taveira, A. Mendes, Ind. Eng. Chem. Res. 2011, 50, $10201-10210$.

[12] P. Kanchanalai, R. P. Lively, M. J. Realff, Y. Kawajiri, Ind. Eng. Chem. Res. 2013, 52, 11132-11141.

[13] a) A. A. Askalany, M. Salem, I. M. Ismael, A. H. H. Ali, M. G. Morsy, B. B. Saha, Renewable Sustainable Energy Rev. 2013, 19, 565-572; b) H. Demir, M. Mobedi, S. Ulku, Renewable Sustainable Energy Rev. 2008, 12, $2381-2403$; c) M. S. Fernandes, G. J. V. N. Brites, J. J. Costa, A. R. Gaspar, V. A. F. Costa, Renewable Sustainable Energy Rev. 2014, 39, 102-123; d) M. Sultan, I. I. El-Sharkawy, T. Miyazaki, B. B. Saha, S. Koyama, Renewable Sustainable Energy Rev. 2015, 46, 16-29.

[14] E. P. Ng, S. Mintova, Microporous Mesoporous Mater. 2008, 114, 1-26.

[15] N. C. Srivastava, I. W. Eames, Appl. Therm. Eng. 1998, 18, 707-714.

[16] N. C. Burtch, H. Jasuja, K. S. Walton, Chem. Rev. 2014, 114, 10575-10612.

[17] S. Lowell, J. E. Shields, M. A. Thomas, M. Thommes, Characterization of Porous Solids and Powders: Surface Area, Pore Size and Density, Vol. 16, Springer Netherlands, 2004.

[18] M. W. Anderson, J. Klinowski, J. Chem. Soc. Faraday Trans. 1 1986, 82, $1449-1469$.

[19] J. Weitkamp, P. Kleinschmit, A. Kiss, C. H. Berke, in Proceedings of the Ninth International Zeolite Conference (Eds.: R. von Ballmoos, J. B. Higgins, M. M. J. Treacy), Butterworth-Heinemann, Stoneham, MA, 1993.

[20] A. Giaya, R. W. Thompson, R. Denkewicz, Microporous Mesoporous Mater. 2000, 40, 205-218.

[21] J. Canivet, A. Fateeva, Y. Guo, B. Coasne, D. Farrusseng, Chem. Soc. Rev. 2014, 43, 5594-5617.

[22] a) P. D. Sullivan, B. R. Stone, Z. Hashisho, M. J. Rood, Adsorption 2007, 13, 173-189; b) K. V. Kumar, K. Preuss, Z. X. Guo, M. M. Titirici, J. Phys. Chem. C 2016, 120, 18167-18179.

[23] Ashrae, 2015 ASHRAE Handbook: HVAC Applications, Ashrae, Atlanta, 2015.

[24] T. C. Drage, C. E. Snape, L. A. Stevens, J. Wood, J. Wang, A. I. Cooper, R. Dawson, X. Guo, C. Satterley, R. Irons, J. Mater. Chem. 2012, 22, 28152823.
[25] S. Mintova, S. Y. Mo, T. Bein, Chem. Mater. 2001, 13, 901 -905.

[26] D. H. Olson, W. O. Haag, W. S. Borghard, Microporous Mesoporous Mater. 2000, 35-36, 435-446.

[27] a) B. Hunger, O. Klepel, C. Kirschhock, M. Heuchel, H. Toufar, H. Fuess, Langmuir 1999, 15, 5937-5941; b) F. M. Higgins, N. H. de Leeuw, S. C. Parker, J. Mater. Chem. 2002, 12, 124-131.

[28] M. Tatlier, G. Munz, S. K. Henninger, Microporous Mesoporous Mater. 2018, 264, 70-75

[29] a) L. F. Scatena, M. G. Brown, G. L. Richmond, Science 2001, 292, 908 912 ; b) K. Koga, G. T. Gao, H. Tanaka, X. C. Zeng, Nature 2001, 412, $802-$ 805 .

[30] L. Liu, S. J. Tan, T. Horikawa, D. D. Do, D. Nicholson, J. Liu, Adv. Colloid Interface Sci. 2017, 250, 64-78.

[31] Y. Tao, H. Muramatsu, M. Endo, K. Kaneko, J. Am. Chem. Soc. 2010, 132, $1214-1215$.

[32] T. Ohba, Angew. Chem. Int. Ed. 2014, 53, 8032-8036; Angew. Chem. 2014, 126, 8170-8174.

[33] T. Ohba, H. Kanoh, M. Yudasaka, S. lijima, K. Kaneko, in CD Proceedings of the International Carbon Conference, Biarritz, France, 2009.

[34] H. Sakamoto, T. Fujimori, X. L. Li, K. Kaneko, K. Kan, N. Ozaki, Y. Hijikata, S. Irle, K. Itami, Chem. Sci. 2016, 7, 4204-4210.

[35] M. Nakamura, T. Ohba, P. Branton, H. Kanoh, K. Kaneko, Carbon 2010, 48, 305-308.

[36] T. Horikawa, T. Muguruma, D. D. Do, K. I. Sotowa, J. R. Alcantara-Avila, Carbon 2015, 95, 137-143.

[37] M. Thommes, J. Morell, K. A. Cychosz, M. Froba, Langmuir 2013, 29, $14893-14902$.

[38] P. Lodewyckx, Carbon 2010, 48, 2549-2553.

[39] N. Qi, M. D. LeVan, Carbon 2005, 43, 2258-2263.

[40] D. D. Do, S. Junpirom, H. D. Do, Carbon 2009, 47, 1466-1473.

[41] L. Cossarutto, T. Zimny, J. Kaczmarczyk, T. Siemieniewska, J. Bimer, J. V. Weber, Carbon 2001, 39, 2339-2346.

[42] T. Ohba, K. Kaneko, Langmuir 2011, 27, 7609-7613.

[43] G. P. Hao, G. Mondin, Z. Zheng, T. Biemelt, S. Klosz, R. Schubel, A. Eychmuller, S. Kaskel, Angew. Chem. Int. Ed. 2015, 54, 1941-1945; Angew. Chem. 2015, 127, $1962-1967$.

[44] X. L. Sun, G. P. Hao, X. Y. Lu, L. X. Xi, B. Liu, W. P. Si, C. S. Ma, Q. M. Liu, Q. Zhang, S. Kaskel, O.G. Schmidt, J. Mater. Chem. A 2016, 4, 10166 10173.

[45] E. Zhang, G. P. Hao, M. E. Casco, V. Bon, S. Gratz, L. Borchardt, J. Mater. Chem. A 2018, 6, 859-865.

[46] G. P. Hao, N. R. Sahraie, Q. Zhang, S. Krause, M. Oschatz, A. Bachmatiuk, P. Strasser, S. Kaskel, Chem. Commun. 2015, 51, 17285-17288.

[47] L. Stegbauer, M. W. Hahn, A. Jentys, G. Savasci, C. Ochsenfeld, J. A. Lercher, B. V. Lotsch, Chem. Mater. 2015, 27, 7874-7881.

[48] D. Mullangi, S. Nandi, S. Shalini, S. Sreedhala, C. P. Vinod, R. Vaidhyanathan, Sci. Rep. 2015, 5, 10876.

[49] B. P. Biswal, S. Kandambeth, S. Chandra, D. B. Shinde, S. Bera, S. Karak, B. Garai, U. K. Kharul, R. Banerjee, J. Mater. Chem. A 2015, 3, 23664-23669.

[50] S. Karak, S. Kandambeth, B. P. Biswal, H. S. Sasmal, S. Kumar, P. Pachfule, R. Banerjee, J. Am. Chem. Soc. 2017, 139, 1856-1862.

[51] P. Kuhn, M. Antonietti, A. Thomas, Angew. Chem. Int. Ed. 2008, 47, 3450-3453; Angew. Chem. 2008, 120, 3499-3502.

[52] S. Ren, M. J. Bojdys, R. Dawson, A. Laybourn, Y. Z. Khimyak, D. J. Adams, A. I. Cooper, Adv. Mater. 2012, 24, 2357-2361.

[53] S. N. Talapaneni, T. H. Hwang, S. H. Je, O. Buyukcakir, J.W. Choi, A. Coskun, Angew. Chem. Int. Ed. 2016, 55, 3106-3111; Angew. Chem. 2016, 128, 3158-3163.

[54] S. Y. Yu, J. Mahmood, H. J. Noh, J. M. Seo, S. M. Jung, S. H. Shin, Y. K. Im, I. Y. Jeon, J. B. Baek, Angew. Chem. Int. Ed. 2018, 57, 8438-8442; Angew. Chem. 2018, 130, 8574-8578.

[55] K. Wang, L. M. Yang, X. Wang, L. Guo, G. Cheng, C. Zhang, S. Jin, B. Tan, A. Cooper, Angew. Chem. Int. Ed. 2017, 56, 14149-14153; Angew. Chem. 2017, 129, 14337-14341.

[56] a) M. Liu, Q. Huang, S. Wang, Z. Li, B. Li, S. Jin, B. Tan, Angew. Chem. Int. Ed. 2018, 57, 11968-11972; Angew. Chem. 2018, 130, 12144-12148; b) M. Liu, K. Jiang, X. Ding, S. Wang, C. Zhang, J. Liu, Z. Zhan, G. Cheng, B. Li, H. Chen, S. Jin, B. Tan, Adv. Mater. 2019, 31, 1807865.

[57] H. Yu, C. J. Shen, M. Z. Tian, J. Qu, Z. G. Wang, Macromolecules 2012, 45, 5140-5150. 
[58] S. Hug, L. Stegbauer, H. Oh, M. Hirscher, B. V. Lotsch, Chem. Mater. 2015, 27, $8001-8010$.

[59] J. Artz, R. Palkovits, ChemSusChem 2015, 8, 3832-3838.

[60] S. Dey, A. Bhunia, D. Esquivel, C. Janiak, J. Mater. Chem. A 2016, 4, $6259-6263$.

[61] a) S. Dey, A. Bhunia, I. Boldog, C. Janiak, Microporous Mesoporous Mater. 2017, 241, 303-315; b) S. Dey, A. Bhunia, H. Breitzke, P. B. Groszewicz, G. Buntkowsky, C. Janiak, J. Mater. Chem. A 2017, 5, 3609-3620.

[62] O. Buyukcakir, S. H. Je, S. N. Talapaneni, D. Kim, A. Coskun, ACS Appl. Mater. Interfaces 2017, 9, 7209-7216.

[63] K. Park, K. Lee, H. Kim, V. Ganesan, K. Cho, S. K. Jeong, S. Yoon, J. Mater. Chem. A 2017, 5, 8576-8582.

[64] G. B. Wang, K. Leus, H. S. Jena, C. Krishnaraj, S. N. Zhao, H. Depauw, N. Tahir, Y. Y. Liu, P. Van der Voort, J. Mater. Chem. A 2018, 6, 6370-6375.

[65] Q. Chen, D. P. Liu, J. H. Zhu, B. H. Han, Macromolecules 2014, 47, $5926-$ 5931.

[66] L. J. Feng, Q. Chen, J. H. Zhu, D. P. Liu, Y. C. Zhao, B. H. Han, Polym. Chem. 2014, 5, $3081-3088$

[67] G. Li, B. Zhang, Z. Wang, Macromol. Rapid Commun. 2014, 35, 971 - 975.

[68] G. Y. Li, B. Zhang, J. Yan, Z. G. Wang, J. Mater. Chem. A 2016, 4, $11453-$ 11461.

[69] M. M. Abdelnaby, A. M. Alloush, N. A. A. Qasem, B. A. Al-Maythalony, R. B. Mansour, K. E. Cordova, O. C. S. Al Hamouz, J. Mater. Chem. A 2018, $6,6455-6462$
[70] G. W. Peterson, O. K. Farha, B. Schindler, P. Jones, J. Mahle, J. T. Hupp, J. Porous Mater. 2012, 19, 261 - 266.

[71] F. M. Wisser, K. Eckhardt, D. Wisser, W. Bohlmann, J. Grothe, E. Brunner, S. Kaskel, Macromolecules 2014, 47, 4210-4216.

[72] N. Popp, T. Homburg, N. Stock, J. Senker, J. Mater. Chem. A 2015, 3, $18492-18504$.

[73] C. Klumpen, M. Breunig, T. Homburg, N. Stock, J. Senker, Chem. Mater. 2016, 28, $5461-5470$.

[74] J. Byun, H. A. Patel, D. Thirion, C. T. Yavuz, Polymer 2017, 126, 308-313.

[75] Y. Byun, A. Coskun, Angew. Chem. Int. Ed. 2018, 57, 3173-3177; Angew. Chem. 2018, 130, 3227-3231.

[76] M. Rose, N. Klein, W. Böhlmann, B. Böhringer, S. Fichtner, S. Kaskel, Soft Matter 2010, 6, 3918-3923.

[77] K. V. Rao, S. Mohapatra, T. K. Maji, S. J. George, Chem. Eur. J. 2012, 18, 4505- 4509 . 